\title{
The Mechanism of Tonic Inhibition of Crayfish Escape Behavior: Distal Inhibition and Its Functional Significance
}

\author{
Eric T. Vu, Sunhee C. Lee, and Franklin B. Krasne \\ Neuroscience Program, Department of Psychology, and the Brain Research Institute, University of California at Los \\ Angeles, Los Angeles, California 90024
}

The excitability of crayfish escape behavior is seldom fully predictable. A major determinant of this fickleness is a form of descending inhibition that is reliably evoked during restraint or feeding and is called "tonic inhibition." Tonic inhibition was found to inhibit postsynaptically the lateral giant neurons, the command neurons for one form of escape. This inhibition is located on lateral giant dendrites that are electrotonically distant from the neuron's spike initiating zone. In contrast, the postsynaptic inhibition due to "recurrent inhibition," which prevents new escape responses from starting while a previously initiated one is in process, occurs proximally, near the spike initiating zone. The distalness of tonic inhibition could be an adaptation for selective suppression of parts of the lateral giant dendritic tree. Consistent with this, evidence was obtained that the tonic inhibitory system can suppress responses to specific sensory fields. An independent reason for targeting recurrent inhibition proximally and tonic inhibition distally was suggested by the functional requirements of each inhibitory process: recurrent inhibition needs to be "absolute" in the sense that the response should be absolutely prevented, whereas it must be possible to override tonic inhibition. Neuronal models demonstrated that proximal inhibition gives recurrent inhibition the required property of absoluteness while distal inhibition allows tonic inhibition to be overridden ("relativity"). It was shown that the relativity of distal inhibition arises from its interaction with the process of saturation of excitation and that tonic inhibition does indeed interact with excitatory saturation as predicted. It is suggested that the property of relativity of distal inhibition is exploited in other nervous systems as well.

IKey words: remote inhibition, crayfish, lateral giant, escape, tonic inhibition, distal inhibition, neuronal integration, neural computation]

In recent years much progress has been made in elucidating neural mechanisms underlying alterations of behavioral responsiveness. In particular, habituation and sensitization of Aplysia defensive withdrawal responses and of crayfish lateral giant escape reaction, a short-latency stereotyped abdominal

\footnotetext{
Received Sept. 18, 1992; revised Apr. 7, 1993; accepted Apr. 19, 1993.

We thank Terri Teshiba for technical assistance. This research was supported by a predoctoral NSF fellowship to E.T.V. and by NINDS Grant NS-08108 to F.B.K.

Correspondence should be addressed to Dr. Eric Vu, Division of Biology $216-$ 76, Caltech, Pasadena, CA 91125.

Copyright (C) 1993 Society for Neuroscience $0270-6474 / 93 / 134379-15 \$ 05.00 / 0$
}

flexion, have been explained in terms of changes in intrinsic properties of synapses in the pathways mediating the responses (Krasne, 1969; Zucker, 1972b; Kandel and Schwartz, 1982; Krasne and Glanzman, 1986; Byrne, 1987; Kandel et al., 1987). In crayfish, substantial changes in behavioral excitability of lateral giant escape can also be produced by a descending modulatory influence referred to as "tonic inhibition" (TI) (Krasne and Wine, 1975; Krasne et al., 1990; Vu and Krasne, 1992).

The circumstances that evoke TI are not fully understood. Often it is responsible for dramatic and seemingly capricious swings in the sensory threshold for lateral giant escape responses. However, it is known that if animals are restrained, TI is usually activated, frequently making it extremely difficult to elicit escape. Suppression in this situation is presumably part of a strategy to hold off escape until a timely moment when a flip might succeed in freeing the animal (see Krasne and Wine, 1975). Also, when crayfish are engaged in feeding behavior, TI decreases the likelihood that the feeding animal will respond to modest threats by escaping (Bellman and Krasne, 1983; Krasne and Lee, 1988). Thus, TI is a biologically significant modulator of escape. It is clearly involved in the essential process of coordinating between competing behaviors and, given its sometimes capricious operation, probably has further behavioral roles. Thus, it provides a useful model for analyzing the means by which nervous systems extrinsically modulate the excitability of selected behavior patterns. The purpose of this study was to begin to investigate the mechanisms of TI at the cellular level.

The neural circuit mediating lateral giant escape reactions is known with great detail (Krasne and Wine, 1984, 1987; Wine, 1984; Fraser and Heitler, 1989, 1991; Edwards et al., 1991): major elements of the circuit have been identified, and their synaptic connectivity and functional roles determined. It was previously established that TI descends from more rostral ganglia of the crayfish CNS to the abdomen, where the escape circuit is located (Krasne and Wine, 1975; Krasne and Lee, 1988). Previous work using extracellular recording in chronic preparations had also suggested that TI selectively gates transmission to the lateral giant command neurons (LGs) from their direct afferents without affecting earlier sensory or later motor parts of the circuit (Krasne and Wine, 1975; Krasne and Lee, 1988). In this, TI differs from another previously well-studied form of inhibition, recurrent inhibition, which directly inhibits the LG neurons but also affects a number of other sites within escapemediating circuitry (Roberts, 1968; Wine and Krasne, 1982; Kirk and Wine, 1984; Kirk, 1985). Recurrent inhibition, which operates during tail flip movements to prevent a new response from starting until an ongoing one is completed and whose 

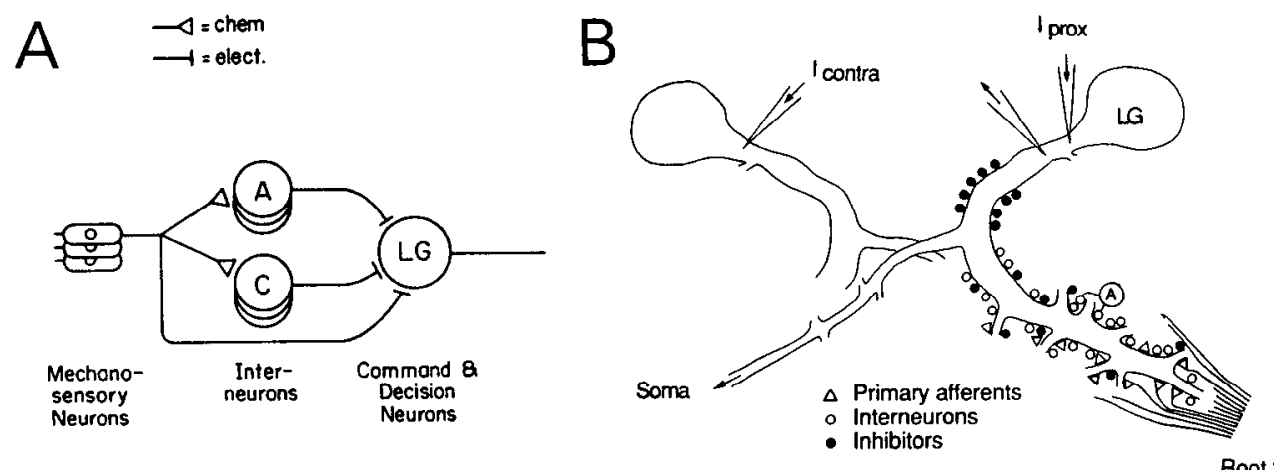

Figure 1. Anatomical background. $A$, Schematic diagram of the sensory side of the neural circuit with identified neurons labeled ( $A$ and $C$, sensory interncurons A and C; $L G$, lateral giant). $B$, Cartoon representation of $L G$ dendrites based on an electron microscopic analysis (Lee and Krasne, 1993) and showing sites of electrode placement. Plane of paper represents a coronal section of a middle abdominal ganglion; dorsal is up. The bilateral LG axons are located dorsolaterally and run rostrocaudally. Part of the contralateral LG is drawn, along with the approximate site of the commissural synapse near the midline of the ganglion. Relative distribution of anatomically classified inputs is shown, as well as the approximate site of input from interneuron A (small circle labeled $A$ ). $I_{\text {prox }}$, current injected into the axon initial segment, proximal to the recording electrode; $I_{\text {contra }}$, current injected into the contralateral LG axon initial segment.

mechanisms are well analyzed, provided an important reference point for the present analysis of TI (for other instances of crayfish escape suppression, see also Edwards et al., 1988; Beall et al., 1990).

Preliminary reports of the work presented here have been published previously (Vu and Krasne, 1988, 1989, 1991; Krasne et al., 1990, 1991).

\section{Materials and Methods}

\section{Subjects}

Crayfish (Procambarus clarkii) of both sexes measuring 8-11 cm from rostrum to telson were obtained from various local suppliers and maintained individually.

\section{Anatomical background}

The neural circuit afferent to the LGs is diagrammed in Figure $1 A$. Mechanosensitive primary afferents in each abdominal segment excite the LGs both monosynaptically via electrical synapses and disynaptically via cholinergic excitation of a group of sensory interneurons (INs) that make electrical synapses on the LGs (Zucker, 1972a; Miller et al., 1992). The classically described bilateral LG axons (Johnson, 1924) are actually chains of segmental neurons joined end to end by very efficient electrical "septal" junctions. They also communicate across the midline in each ganglion by electrical "commissural" junctions (Watanabe and Grundfest, 1961). Interneuron A is an identified sensory interneuron (Kennedy, 1971; Sigvardt et al., 1982) that makes electrical synapses with the LG of each abdominal ganglion except the sixth. Figure $1 B$ is a representation of the LG dendrites in a middle abdominal ganglion, indicating the location of their inputs. Terminals with elongated synaptic vesicles typical of GABAergic inhibitors are intermixed with those from excitors distally (relative to the axon) and also occur by themselves proximally (Krasne et al., 1990; Lec and Krasnc, 1993).

\section{Physiological preparations}

Two types of preparation were used.

Intact preparation. This preparation was used to characterize TI at the behavioral and network level. To induce TI, animals were held with rubber bands, ventral side up, to a platform in a water-filled chamber. The thorax was swaddled with wet gauze and the abdomen immobilized with clips. The recording and stimulating electrodes used, the criteria for identification of IN A and LG action potentials, and the "threshold tracking" procedure were as previously described (Krasne and Glanzman, 1986). Briefly, stimulating electrodes were placed against roots $2-$ 4 of the last abdominal ganglion and stimulus levels were continuously varied so as to maintain a running estimate of the firing threshold for the unit under observation. Stimuli were delivered once per minute, with the stimulus level set near the expected threshold for either IN A or LG on alternate trials. Nerve cord severance during some sessions was made between the last thoracic and first abdominal ganglia, with care to spare the overlying ventral artery.

Semi-intact preparation. To avoid blood clots, animals were gradually cooled to $5^{\circ} \mathrm{C}$ and then their hemolymph was replaced with cold, aerated Ringer's solution (Van Harreveld, 1936) at a rate of $3 \mathrm{ml} / \mathrm{min}$ via a 23 gauge hypodermic needle inserted into the first joint of a cheliped. The exsanguination outlet was a small window made by removal of the sixth abdominal sternum. To maintain blood pressure to the brain, the ventral artery was ligated just caudal to where it is joined by the arteria descendens between the third and fourth thoracic ganglia.

Abdominal motor roots were cut to eliminate abdominal movements. To prevent struggling movements of the thorax from dislodging inserted microelectrodes, an abdominal connective rostral to the site of microelectrode insertion was bonded with cyanoacrylate glue (Vetbond) to a size 3 insect pin (Wards) lodged between the pleural plates of that segment. The animal was then restrained either ventral or dorsal side up in a chamber filled with chilled Ringer's solution. In dorsal-side-up preparations, the terga of the abdomen were removed, the dorsal artery and gut were ligated at the level of the first abdominal ganglion, and their caudal portions were cut and removed. The flexor musculature was then separated at the midline to expose the ventral nerve cord (Krasne, 1969). The rostral, dorsal portion of either the fourth or sixth abdominal ganglion was then desheathed, and LG was impaled with one or two microelectrodes just rostral to the septal junction. Platinum hook electrodes were used to stimulate primary afferent fibers in the ipsilateral second root of the fourth ganglion or the first root of the sixth ganglion. In order to impale LG in ventral-side-up preparations, the sternum overlying either the fourth or sixth abdominal ganglion was removed, as was the ventral sheath at the rostral edge of the ganglion, and then the ganglion was supported dorsally and the microelectrode was lowered from the ventral surface of the ganglion to the dorsally located LG.

In some preparations, the connective between the first and second abdominal ganglia was prepared for sucrose block of action potential propagation across the connective. The connective was desheathed and isolated from the circulating Ringer's solution by a chamber made from a piece of tubing (PE 320) sealed to a base with petroleum jelly. The chamber content was then either Ringer's solution or an isotonic sucrose solution $(416 \mathrm{~mm})$

\section{Stimulation and recording}

Single-barrel microelectrodes $(2.5 \mathrm{M} \mathrm{K}$-acetate filled, $10-30 \mathrm{M} \Omega$ resistance) were used to impale LG just rostral to the septal junction, at the axon initial segment. To evoke recurrent inhibition, the medial giant axon was electrically stimulated via a focal pin electrode. The axon of IN A was similarly stimulated on the ventral side of a hemiconnective ipsilateral to the impaled LG. All stimuli were $0.1 \mathrm{msec}$ pulses; all constant current injections were at least $60 \mathrm{msec}$ long. Large (>100 nA) 
current pulses injected into the contralateral LG were measured by a virtual ground circuit. Stimulating and recording equipment were standard. Signals were digitized by a Metrabyte DAS- 20 board and stored in an IBM AT-compatible computer.

\section{Statistical procedures}

All statistical tests were two-tailed Student's $t$ tests of independent samples with pooled estimates of variance, except as noted. Error bars in all figures are SEM. (While developing the semi-intact preparation, we initially recorded from a few animals that did not show descending inhibition, probably because of damage to their CNS during the extensive surgery. Once the semi-intact preparation was well developed, wc no longer encountered noninhibiting animals. Therefore, the early preparations were not included in statistical analyses.)

\section{Neuronal modeling}

Passive compartmental models of dendritic arbors were constructed using the IBM-DOS-based program NEURON developed and kindly provided by Dr. D. H. Edwards of Georgia State University (see Edwards, $1990 \mathrm{~b}$ ). The program was used to simulate the behaviors of a uniform passive cable and a tapering cable model (see Rall, 1964), each with 10 compartments.

An anatomically realistic model of the LG dendritic arbor was also constructed from measurements of cobalt back-filled LG neurons viewed in whole-mount (see Lee and Krasne, 1993). The parameters specified for construction of the model were as follows: membrane time constant of $3.0 \mathrm{msec}$ (E. T. Vu, unpublished physiological measurements; see also Edwards et al., 1991), membrane capacitance of $1 \mu \mathrm{F} / \mathrm{cm}^{2}$, specific membrane resistance of $3000 \Omega \cdot \mathrm{cm}^{2}$ (derived from values of membrane time constant and capacitance), cytoplasmic resistance of $60 \Omega \cdot \mathrm{cm}$, and the various lengths and diameters of the 30 compartments of the model. The smallest dendritic compartment had a length of $15 \mu \mathrm{m}$ and diameter of $2 \mu \mathrm{m}$; the largest dendritic compartment, a $200 \mu \mathrm{m}$ length and 35 $\mu \mathrm{m}$ diameter; and the axonal compartment, a $8000 \mu \mathrm{m}$ length and 100 $\mu \mathrm{m}$ diameter (see Fig. 13). Excitation and inhibition of selected compartments were modeled with parallel electrical paths across the membrane with time-varying resistances in series with batteries (see Fig. 12). The excitatory reversal potential was $+80 \mathrm{mV}$ from resting potential and the inhibitory reversal potential was $+4 \mathrm{mV}$.

The behaviors of the two-compartment models shown in Figure 12 were obtained from analytical solutions for the value of the voltage of the proximal compartment.

\section{Results}

\section{Effects of restraint on escape behavior}

We first confirmed that the restraining procedures used in this study reliably evoked and maintained suppression of escape behavior. In Figure 2, an intact preparation was continuously restrained at the beginning of the session, and a running estimate of the firing thresholds for IN A and LG was obtained. After about $40 \mathrm{~min}$, the threshold for LG firing abruptly rose to a high level, whereas that for IN A firing did not change. Severing the nerve cord between thorax and abdomen, thus interrupting any descending influence, caused the LG threshold but not the threshold of IN A to drop rapidly to a low and steady value. Similar results were obtained in eight other preparations, confirming previous observations that TI originates in rostral parts of the CNS and affects transmission between primary afferents and LG without affecting transmission between afferents and sensory INs.

Most naive animals took a period of minutes to begin tonically inhibiting under these circumstances. We have also found that animals tend to inhibit more rapidly and perhaps more strongly during subsequent restraint sessions (E. T. Vu, K. Kawamura, and F. B. Krasne, unpublished observations). The long latency to inhibit and its variability between sessions suggest that TI is not a purely reflexive reaction to restraint.

We found that animals can often be provoked to begin in-
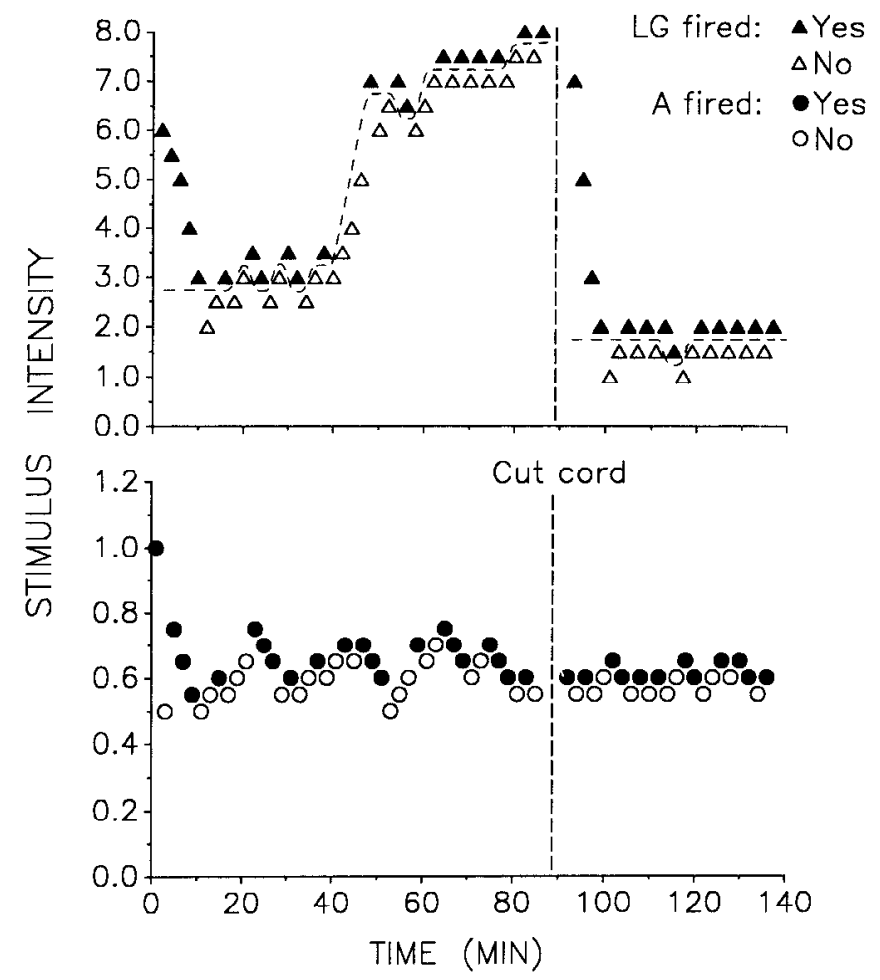

Figure 2. Thresholds for LG and IN A firing in restrained crayfish before and after severing the nerve cord. The dashed curve is a subjective interpretation of the moment-to-moment stimulus threshold for LG firing based on the data points. Note latency of nearly 40 min after start of restraint before animal began to inhibit escape.

hibiting by presenting them with a small object to hold with their chelipeds (see Figs. 10,11). Once escape suppression was evoked in this manner, it outlasted by far the period during which the object was presented.

\section{$T I$ in semi-intact preparations}

In order to discover the cellular mechanism for reduced transmission to $I G$, intracellular $I G$ recordings were made in semiintact preparations (see Materials and Methods). Due to the necessary surgery, recording sessions usually began after animals had been restrained for about $2 \mathrm{hr}$, by which time TI should be continuously active. To confirm this, a sucrose block of a connective rostral to the recording site was used in order to compare periods with and without descending influence.

Afferent fibers of an ipsilateral segmental root were electrically stimulated once every $2 \mathrm{~min}$ at a constant stimulus strength. These brief stimuli produce a long-lasting, compound EPSP in LG (Fig. $3 A$ ), with the first, $\alpha$-component produced by monosynaptic input from primary afferents via electrical synapses, and the $\beta$ - and later components produced by input from sensory INs excited by the afferents (see Fig. $1 A$ ). The dashed trace in Figure $3 A$ was a representative root-evoked EPSP recorded early in a session. When sucrose block was then applied, the EPSP increased (continuous trace), and it was again reduced when the block was removed (not shown). In Figure $3 B$, the peak EPSP size was repeatedly measured, and time-matched values from four preparations were pooled. For each animal, all values were normalized to the mean value during the first sucrose block period. The EPSP was significantly larger during sucrose block (Fig. $3 B$, left side; $C$, 1st vs $2 \mathrm{~d}$ bar; $t_{3}=11.52, p<0.01$, two- 
Figure 3. Effect of sucrose connective block and cord severance on LG rootevoked EPSP in semi-intact preparation. $A$, Compound subthreshold EPSP recorded in $L G$ to root stimulation. Clipped downward deflection is the stimulus artifact. See Results for origins of the $\alpha$ - and $\beta$-components. Two traces from the same preparation are overlapped with their baselines superimposed: the continuous trace was recorded during sucrose block; the dashed trace, immediately before this. $B$, Normalized size of peak of root-evoked EPSP over the cntirc session. Timematched data from four preparations were pooled. Sucrose, periods during which sucrose connective block of descending pathways was applied. At about minute 49 , the nerve cord was cut between thorax and abdomen. $C$, For each of the four animals in $B$, the mean normalized EPSP values across periods of sucrose block and unblock, before and after cord severance, were determined. The averages of these across animals are shown.
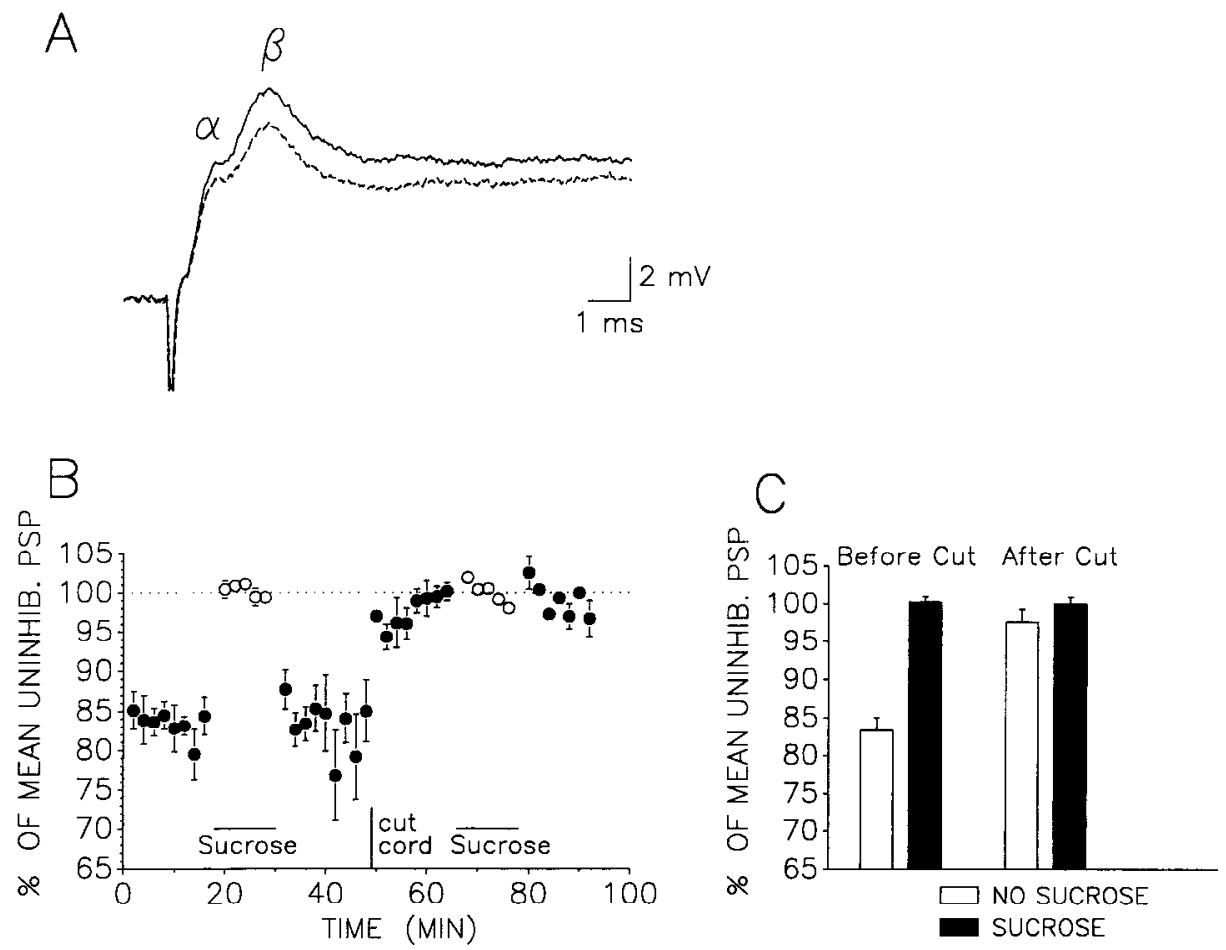

tailed $t$ test with Welch estimate of variance, due to unequal variances between groups; see below), and the effect was fully reversible.

A different but irreversible method of disinhibition was to sever the nerve cord between thorax and abdomen (rostral to the sucrose chamber), as had been done in intact preparations. This also caused the root EPSP to increase abruptly, and afterward sucrose block no longer caused an EPSP increase (Fig. $3 B$, right side; $C, 3 \mathrm{~d}$ vs 4 th bar, $p>0.05$ ), presumably because TI fibers going through the sucrose chamber were no longer active. Therefore, without TI, sucrose block by itself did not affect sensory transmission in the LG circuit. Thus, TI was shown to be operative in semi-intact preparations, and both sucrose block and cord severance were shown to be effective and equivalent means of disinhibiting the abdominal LG circuit.

\section{Increased variability of root-evoked EPSP during TI}

There was a marked decrease in variability of the root EPSP size during periods of sucrose block (Fig. $3 B$, left side; note smaller error bars during sucrose block). To demonstrate this more clearly, the monosynaptic, electrically transmitted $\alpha$-component was repeatedly measured once every $30 \mathrm{sec}$ in three other preparations. Figure $4 A$ illustrates data from one animal showing that $\alpha$ was noticeably less variable during sucrose block, and Figure $4 B$ shows results pooled across animals. The coefficient of variation ( $\mathrm{SD} / \mathrm{mean}$ ) of measurements taken during sucrose block $(0.024,0.009 \mathrm{SD})$ was significantly different from that of those taken during no block $\left(0.044,0.004 \mathrm{SD} ; t_{6}=4.53, p<\right.$ $0.01)$. Because the variance of an active inhibitory process would be additive to that of the excitatory transmission between afferents and LG, this finding is consistent with the presence of active inhibition in semi-intact preparations that is interrupted by the sucrose block technique. In addition, this indicates that there are detectable fluctuations in the degree of TI on a time scale at least as short as $30 \mathrm{sec}$.

\section{Circuit locus of $T I$}

Threshold-tracking experiments have suggested that transmission between afferents and sensory INs is unaffected during TI, while transmission to $L G$ is reduced. This was evaluated further
Figure 4. Effect of sucrose block on variability of $\alpha$. $A$, Size of $\alpha$ over the entire session for one animal. All values were normalized to the mean value during the sucrose block period. $B$, The coefficients of variation ( $\mathrm{SD} /$ mean) of data obtained before, during, and after the sucrose block were obtained for each animal. Mean values from three animals are shown.
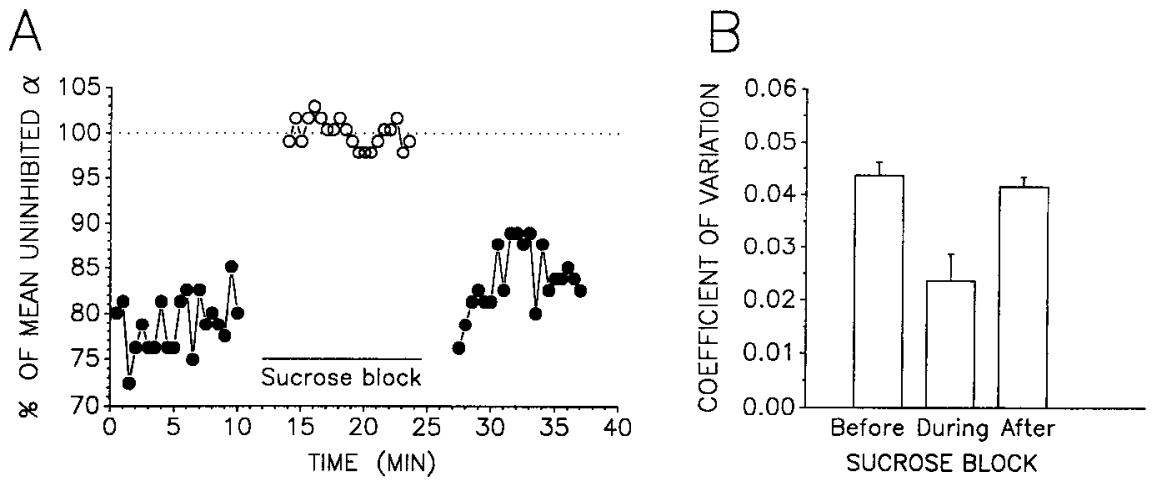


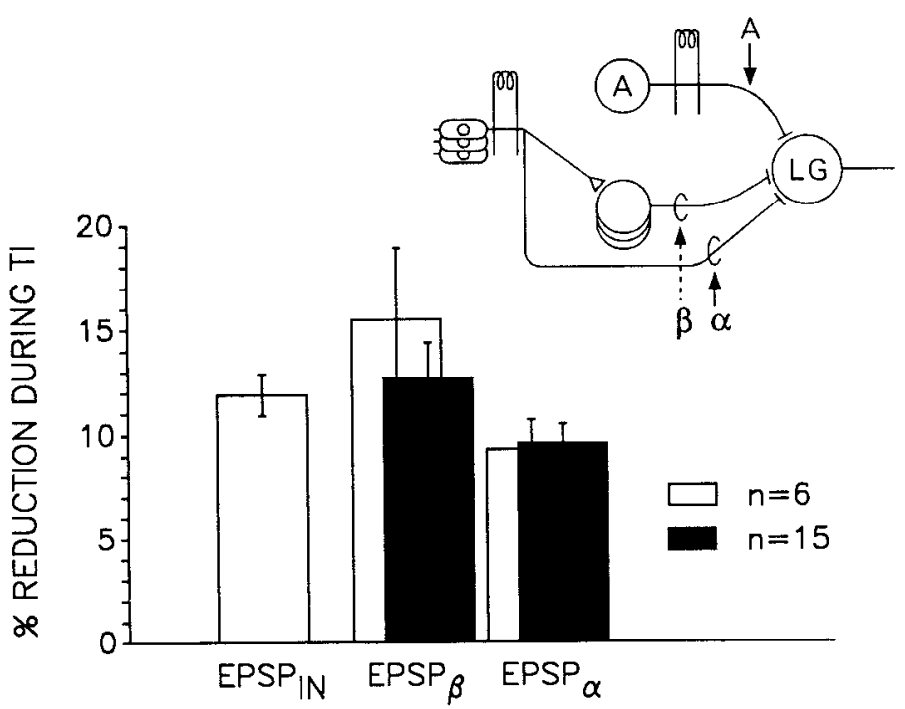

Figure 5. Comparison of reduction by TI of EPSPs from monosynaptic and disynaptic pathways to LG. See inset and Results for origins of EPSPs compared. For the open bars, $N=6 ; N$ was increased to 15 for the solid bars.

by comparing the amount of reduction of the disynaptically produced $\beta$-component of the root-evoked EPSP to reduction of monosynaptic EPSPs produced by selective stimulation of single INs (see Fig. 5 inset). If TI operated primarily at the level of LG, then $\beta$ should be affected to about the same extent as monosynaptic inputs from single INs, whereas if TI also operated at the first synapse of the circuit, then $\beta$ should be much more reduced.

In six animals, the amounts of reduction of $\alpha$ and $\beta$, and of the unitary EPSP produced by electrical stimulation of an IN were determined. For five preparations, the IN whose axon was selectively stimulated was identified as IN A, whereas the unitary EPSP in the remaining preparation was from an unidentified sensory IN. The mean reduction of each type of EPSP was determined for each animal from multiple measurements before and after cord severance.

The mean reduction of $\beta(15.5 \%, 8.2 \mathrm{SD})$ was not significantly different from the reduction either of EPSPs from single sensory INs $(11.9 \%, 2.5 \mathrm{SD})$ or of $\alpha(9.3 \%, 3.5 \mathrm{SD}$; ANOVA for repeated measures, $F=1.65, p>0.05$; Fig. 5 , open bars). However, the reduction of $\alpha$ was slightly less than that of $\beta$ for each of these six animals. When data from nine additional animals were combined with the above data, the mean reduction of $\alpha(9.6 \%, 3.6$ $\mathrm{SD})$ was indeed significantly less than reduction of $\beta(12.7 \%$, $6.4 \mathrm{SD}$; paired $t$ test, $t_{14}=2.262, p<0.05$; Fig. 5, solid bars), though this difference remained slight.

That $\beta$ was not reduced more than EPSPs from single sensory INs indicates that TI operates primarily at the level of LG. The slight difference in $\alpha$ and $\beta$ reductions might arise if the input sites on LG of primary afferents and sensory INs differed with respect to inhibitory input sites and the geometry of the LG neuron. This point needs further study.

\section{Postsynaptic inhibition of $L G$ during $T I$}

Information so far available does not indicate whether the inhibition of transmission to $L G$ is pre- or postsynaptic. To evaluate this further, the LG input resistance was measured during

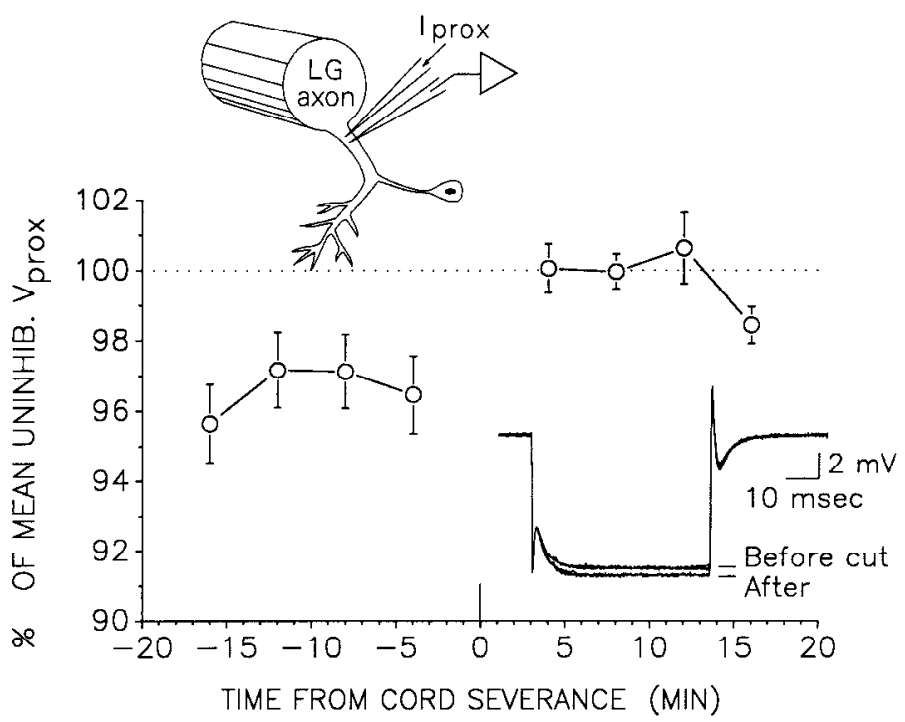

Figure 6. Effect of TI on LG input resistance: normalized size of $V_{\text {prox }}$, the voltage produced by $I_{\text {prox }}$ (see Results and upper left inset), before and after cord severance. Time-matched data from five preparations were pooled. Note that the location of electrode impalement was close (proximal) to the axon. Lower right inset shows three (indistinguishable) traces of $V_{\text {prox }}$ before cut cord and three traces of the larger $V_{\text {prox }}$ after cut, all superimposed.

TI and after disinhibition by cord severance in five dorsal-sideup semi-intact preparations. Two microelectrodes were inserted into the LG axon initial segment, one to inject current and the other to mcasure the resulting voltage change, called $V_{\text {prox }}$ because the current injection was proximal to the recording site. Figure 6 shows that $V_{\text {prox }}$ was reduced by about $3.3 \%$ in the presence of $\mathrm{TI}$, indicating that the $\mathrm{LG}$ input resistance was decreased by TI. The mean normalized value of $V_{\text {prox }}$ before cord severance $(0.967,0.022 \mathrm{SD})$ was significantly different from its mean value after $\left(t_{4}=3.31, p<0.03\right)$.

In six other preparations, the LG membrane potential was carefully monitored and was found to become more negative when sucrose block was applied and to revert to near its previous value when the block was removed (Fig. 7). Therefore, LG was slightly depolarized by TI. (In contrast, disinhibiting animals by cord severance usually caused the membrane potential initially to depolarize by less than $1 \mathrm{mV}$ and then to repolarize slowly to at least its previous level. Due to long-term drifts in our recording system, we could not reliably determine whether the membrane potential then became more hyperpolarized than it was right before the cord was cut. The reason for the slight membrane depolarization right after the cut is not known.)

Thus, $\mathrm{TI}$ is associated with both a conductance increase in LG and a small membrane depolarization, suggesting postsynaptic inhibition of the LGs. The long-lasting LG depolarization produced by TI is not associated with rapid fluctuations in the membrane potential (i.e., with rise or fall times on the order of tens of milliseconds or less) that would indicate temporal summation of more brief inhibitory events. This could be either because the tonic IPSPs have a very slow decay rate, as for example second messenger-mediated postsynaptic potentials tend to have, or because they are generated at a relatively high frequency and at electrotonically distant sites from the axon and our recording site (see below), so they summate smoothly. Identification of tonic inhibitory neurons is needed to address this. 
Figure 7. Effect of sucrose block on LG membrane potential. $A$, Normalized value of membrane potential, $V_{m}$, over the entire session for one animal. The mean recorded membrane potential during sucrose block $\left(E_{r}\right)$ was subtracted from all measures ( $E_{\text {, }}$ values), that is, $V_{m}=E_{m}-E_{r}$. B, Mean values of $V_{m}$ obtained during periods labeled, for six animals. Data from each animal are plotted with a different symbol. In the presence of TI, LG was slightly depolarized.
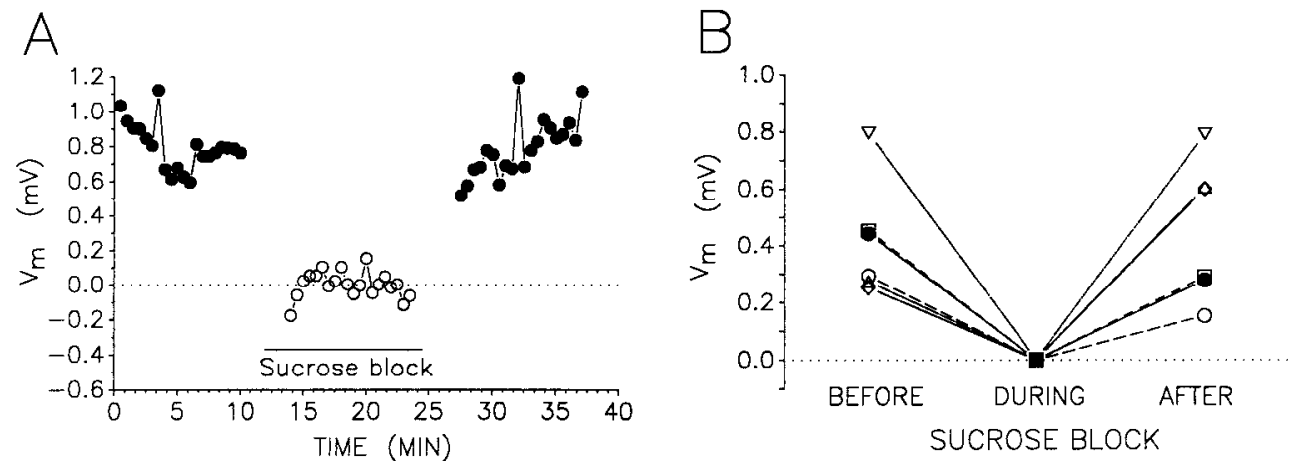

\section{Evidence for different cellular locations for tonic and recurrent inhibition}

Although TI is associated with a conductance increase in LG, the mean reduction of $V_{\text {prox }}$ for the five preparations in Figure 6 seemed markedly less than the 10-12\% reduction of EPSPs for the 15 preparations in Figure 5 . Closer analysis revealed that the reduction of $V_{\text {prox }}$ was in every case less than half that of the root EPSP from the same preparation (Fig. $8 A$, left side; paired $t$ test, $\left.t_{4}=4.02, p<0.02\right)$. In contrast, in analyzing the postsynaptic inhibition of LG by recurrent inhibition, Roberts (1968) found that $V_{\text {prox }}$ reduction was nearly equivalent to reduction of
A

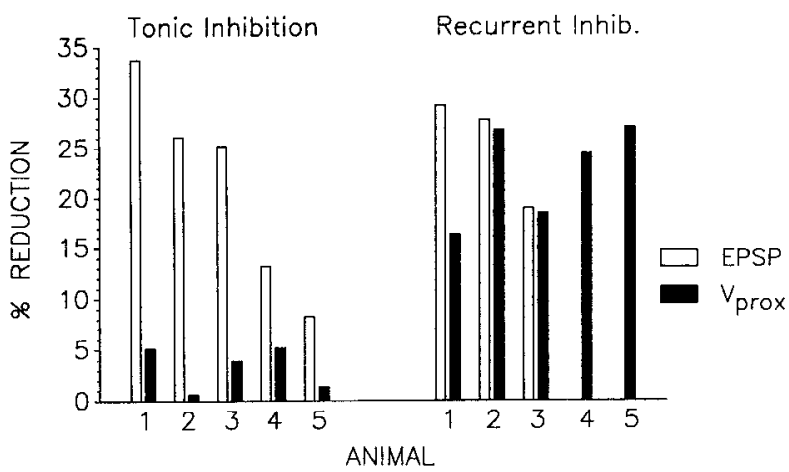

C

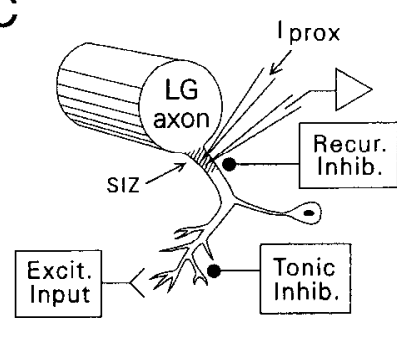

Figure 8. Comparison of attenuation of EPSPs and of $V_{\text {prox }}$ by tonic and recurrent inhibition. $A$, Paired determinations from the same animal of EPSP and $V_{\text {prox }}$ reductions during TI, for five animals, and during recurrent inhibition, for five different animals (for two of which EPSP reduction was not measured). For TI (left side), the EPSP measured was the root-evoked EPSP. For recurrent inhibition (right side), the EPSP was that of IN A. $B$, Mean reduction of $V_{\text {prox }}$ as a fraction of EPSP reduction, calculated from data in $A$. $C$, Cartoon of $\mathrm{LG}$ neuron and electrode placement (SIZ, spike initiating zone). Conjectured fields of excitatory, tonic inhibitory, and recurrent inhibitory inputs are indicated.
EPSPs and concluded that the conductance increase associated with recurrent inhibition was probably located near the electrode impalement site. By analogy, a possible explanation for the comparatively small $V_{\text {prox }}$ reduction by $\mathrm{TI}$ is that its conductance increase is sufficiently distal in the LG dendrites that it shunts excitatory synaptic currents well but shunts poorly the axonally injected test current that produces $V_{\text {prox }}$ (Fig. $8 C$ ).

We have repeated the findings of Roberts on recurrent inhibition ( $\mathrm{Vu}$ and Krasne, 1992). Our data on the reductions of $V_{\text {prox }}$ and of the IN A EPSP are shown on the right side of Figure $8 A$ (like TI, recurrent inhibition reduces different types of monosynaptic LG EPSPs by equivalent amounts; E. T. Vu, unpublished observations). Although tonic and recurrent inhibitions reduced EPSPs by comparable amounts in these experiments (mean of $21.3 \%$ and $25.3 \%$, respectively), recurrent inhibition clearly reduced $V_{\text {prox }}$ more than TI did. To quantify this difference, $V_{\text {prox }}$ reduction was expressed relative to EPSP reduction for each animal and the mean values were compared in Figure $8 B(0.18,0.14 \mathrm{SD}$ for $\mathrm{TI} ; 0.83,0.23 \mathrm{SD}$ for recurrent inhibition; $t_{6}=5.13, p<0.01$ ) (a value of 0.79 for the relative reductions of $V_{\text {prox }}$ and EPSPs by recurrent inhibition can be calculated from the data by Roberts, 1968).

Therefore, it seems likely that recurrent inhibition activates those inhibitory interneurons whose profiles make contacts with LG in the vicinity of the spike initiating segment of the axon (see Fig. $1 B$ and Lee and Krasne, 1993), whereas TI probably does not. We suggest that TI might be mediated by inhibitory synapses located distally on the LG dendrites. Additional support for this is presented below, and Lee and Krasne (1993) provide anatomical evidence for distally located inhibitory synapses on LG (see Fig. $1 B$ ).

Thus, it appears that TI utilizes, at least in part, a different inhibitory pathway than recurrent inhibition because the pathway mediating recurrent inhibition cannot account for the large reduction of EPSPs by TI $(21.3 \%)$ given the small reduction of $V_{\text {prox }}$ by TI $(3.3 \%)$. In fact, because recurrent inhibition was shown to reduce EPSPs by about 1.2 times the amount it reduced $V_{\text {prox }}$, the same pathway could only reduce EPSPs by about $4 \%$ if it reduced $V_{\text {prox }}$ by $3.3 \%$ as TI did. Therefore, the proximal pathway mediating recurrent inhibition would account for less than a fifth ( $4 \%$ vs $21.3 \%$ ) of the amount of EPSP reduction by TI if it were recruited by TI (and this fraction would be an overestimate if the amount of $V_{\text {prox }}$ reduction we measured were due partly to distal inhibition).

\section{Further evidence for distal location of TI}

Ideally, the distal locus of TI might be demonstrated by directly measuring its conductance increase distally. Because distal den- 

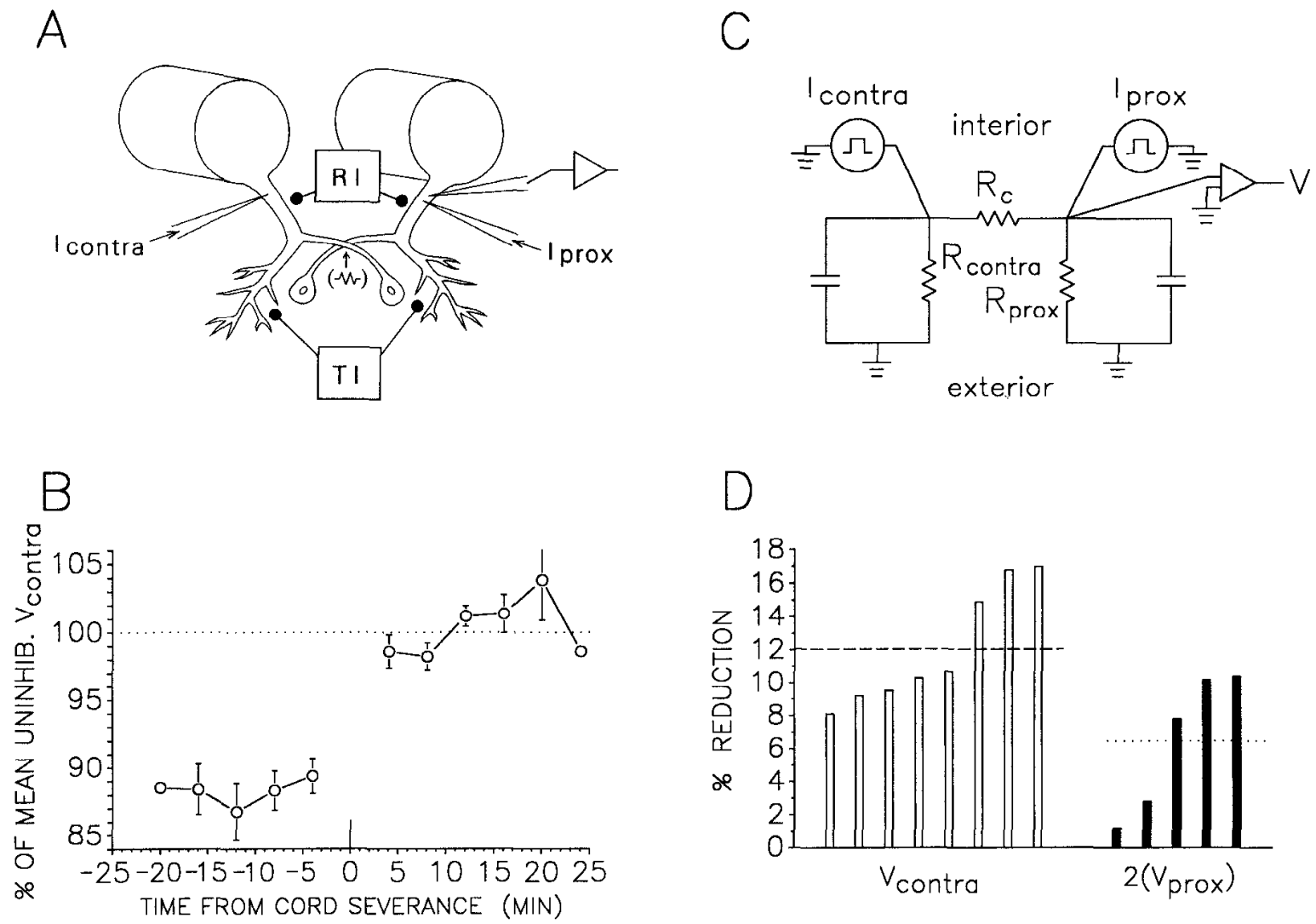

Figure 9. Effect of TI on voltage produced by contralateral current injection ( $\left.V_{\text {contra }}\right)$. $A$, Diagram of bilateral LGs and electrode placement. All measurements were made in the right LG. $V_{\text {contra }}$ was produced by $I_{\text {contra. }}$. The commissural junction is represented by the resistor joining the two LGs. Putative bilateral loci of inhibitions are indicated. $R I$, recurrent inhibition. $B$, Normalized size of $V_{\text {contra }}$ before and after cord cut. Timematched data from eight animals were pooled. $C$, Linear circuit model used to predict relative effects of an exclusively proximal, bilateral inhibition on $V_{\text {contra }}$ and $V_{\text {prox }}$ (see Results). Equivalent batteries for the resting potential were omitted. $D$, Open bars are values of $V_{\text {contra }}$ reduction by TI from eight animals (data from $B$ ). Dashed line is mean of these. Solid bars are values obtained by doubling the $V_{\text {prox }}$ reduction by TI measured in five other animals (same animals as in Fig. 8B). Dotted line is mean of these.

drites were not easily accessible in semi-intact preparations, we conducted the related test of measuring (ipsilaterally) the voltage change produced by current injected into the electrically coupled contralateral LG (Fig. 9A); we call this $V_{\text {contra }}$. Considering the general geometry of LG and the sites of electrode placement and of the commissural junction (about halfway to the most distal dendrites), distally located inhibition might reduce $V_{\text {contra }}$ much more than $V_{\text {prox }}$. Figure $9 B$ shows that TI reduced $V_{\text {conira }}$ by an average of $12.1 \%$ in eight preparations (vs. the $3.3 \%$ for $V_{\text {prox }}$ found above).

While this is consistent with a distal locus, a qualitatively similar prediction would be made for an entirely proximal, but bilateral inhibition. TI acts bilaterally (Krasne and Wine, 1975), and on average probably symmetrically in our undisturbed preparations. Thus, even if TI were entirely proximal, $V_{\text {contra }}$ would still be reduced more than $V_{\text {prox }}$, because the current producing $V_{\text {contra }}^{r}$ would be shunted twice (once near the injection site and once again near the recording site).

To evaluate whether exclusively proximal but bilateral inhibition could account for a $12.1 \%$ reduction of $V_{\text {contra }}$ compared to a $3.3 \%$ reduction of $V_{\text {prox }}$, we used the simple equivalent circuit model shown in Figure $9 C$. Bilateral proximal inhibition corresponds to decreases in the equal values of $R_{\text {prox }}$ and $R_{\text {contra }}$. If $R$ and $R^{\prime}$ are, respectively, the uninhibited and inhibited values of these resistances, then from Kirchhoff's Laws,

$$
\begin{aligned}
\left(V_{\text {prox }}-V_{\text {prox }}^{\prime}\right) / V_{\text {prox }} \cong 1-\left(R^{\prime} / R\right), \\
\left(V_{\text {contra }}-V_{\text {contra }}^{\prime}\right) / V_{\text {contra }} \cong 1-\left(R^{\prime} / R\right)^{2},
\end{aligned}
$$

as long as the commissural reistance $R_{c}$ is large relative to $R$ and $R^{\prime}$, as it appears to be given the large attenuation factor measured across the commissural synapse (Watanabe and Grundfest, 1961). Denoting the above voltage ratios $X_{\text {prox }}$ and $X_{\text {contra }}$, respectively, it follows that

$$
X_{\text {contra }}=2 X_{\text {prox }}-\left(X_{\text {prox }}\right)^{2} \text {, }
$$

or approximately $2 X_{\text {prox }}$ for $X_{\text {prox }}$ values considerably less than unity. Thus, if TI were exclusively proximal, then the reduction of $V_{\text {contra }}$ should be at most twice that of $V_{\text {prox }}$, about $6.6 \%$. However, the actual mean reduction of $V_{\text {contra }}$ was $12.1 \%$ (3.6 $\mathrm{SD}$ ), which was significantly different from the mean value obtained by doubling the $V_{\text {prox }}$ reductions previously measured $\left(6.5 \%, 4.3 \mathrm{SD} ; t_{11}=2.55, p<0.03\right.$; Fig. $\left.9 D\right)$. This observation provides a second line of evidence for the involvement of distal inhibitory synapses in TI.

$\mathrm{Vu}$ and Krasne (unpublished observations) have found that in contrast to TI, recurrent inhibition does reduce $V_{\text {contra }}$ by about twice its $V_{\text {prox }}$ reduction. This both validates the above formulas and suggests that recurrent inhibition has little effect distally. Taken together with the arguments in the previous section, it 

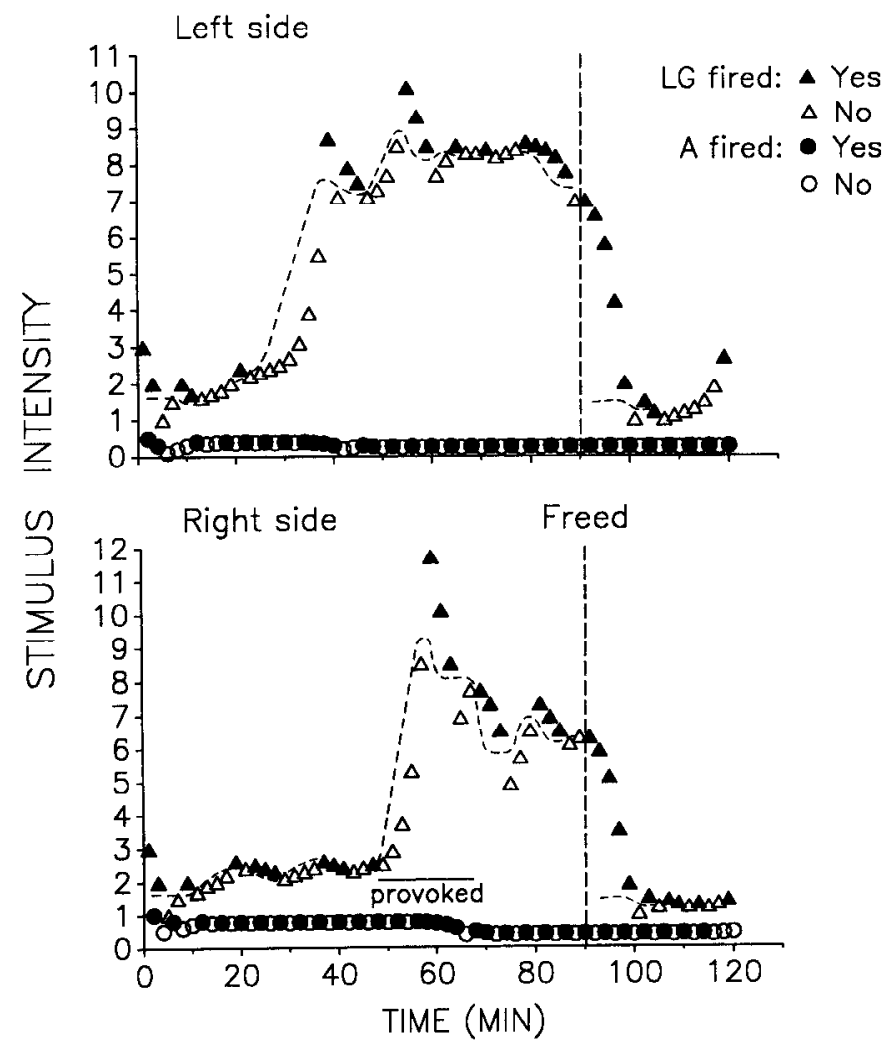

Figure 10. Temporal comparison of thresholds for firing of sixth segment LGs and IN As on the two sides of the animal. Data on top graph are from testing the left-side LG and IN A; those on bottom graph are from testing the right-side neurons. Provocation of animal was presentation of a small object so that it held it continuously with its right cheliped during the period labeled. Animals were returned to their home tank during the "free" period of tracking. Dashed curves are subjective interpretations of the moment-to-moment stimulus threshold for I.G firing based on the data points.

appears that there is very little overlap between the final pathways for recurrent and tonic inhibition.

\section{Selective suppression by the TI system}

A property of distal but not proximal inhibition is the capacity for selective suppression of incoming signals: distal inhibition can in theory inhibit selected dendritic branches that receive inputs from particular origins. To evaluate whether the TI system was capable of selective suppression, we searched for instances in which intact preparations suppressed separate sensory fields by different amounts. The following experiments were not attempts to establish that TI could in fact differentially inhibit portions of the dendritic field of a single LG neuron. Rather, the goal was to determine whether the TI system was in principle capable of exercising some degree of selective control.

It is known that TI on each side of the animal is exclusively produced by ipsilateral projections (Krasne and Wine, 1975). Evidence is presented here that the two sides can be inhibited unequally and asynchronously. Intact preparations were implanted with bilateral stimulating electrodes on sensory roots of the sixth abdominal ganglion. Firing thresholds of both bilateral LGs and bilateral IN As were tracked, the IN A thresholds to ensure that changes in LG threshold were not due to factors other than TI.
Figure 10 illustrates an occasion when the effects of TI on the two sides of the abdomen appeared to be dissociated. The animal was restrained at the start of the session, and the two sides were alternately stimulated once every $30 \mathrm{sec}$, with alternate stimuli on each side set to track either LG or IN A threshold.

About 20 min into the session, the animal began to inhibit strongly its left but not its right side. When it was presented a small object to hold with its right cheliped, the right LG threshold abruptly rose to about four times its previous level, while the left LG threshold increased only slightly. When the object was taken away, the animal continued to inhibit both sides of the abdomen, although inhibition on the right side decreased a small amount. Finally, $\mathrm{LG}$ threshold on both sides rapidly dropped to very low levels when the animal was released. Similar examples of differential inhibition were obtaincd in the other two animals examined in this manner, one of which did not need to be provoked to inhibit. Thus, it appears that the rostral TI centers are at least capable of independently suppressing the two sides of the abdomen.

Inhibition of different segments on the same side could also be independently varied. Figure 11 illustrates the clearest example obtained. Sensory roots on the left side of both the fourth and sixth abdominal ganglia were alternately stimulated, and firing thresholds of the two corresponding segmental LGs and of IN $A$ and a sensory IN recruited by fourth ganglion input were co-tracked. Approximately $30 \mathrm{~min}$ after tie-down, the animal began inhibiting its sixth but not its fourth segment. When it was then presented an object to hold with its right cheliped, it began to inhibit its fourth segment, but for only as long as it was holding the object. However, the fourth segment was spontancously inhibitcd again about $3 \mathrm{~min}$ after the object had becn removed. Meanwhile, inhibition of the sixth segment was so strong during this period that its variations could no longer be followed because of an upper limit to the stimulus strength deliverable.

Finally, to show that these swings in LG threshold were due to $\mathrm{TI}$, the nerve cord was severed between thorax and abdomen. The firing thresholds of both segmental LGs then abruptly decreased to low levels, while those of the two sensory INs remained unchanged. Similar segmental dissociations were observed in all five other animals examined, in which firing thresholds of either the third or fourth and the sixth segment LGs were co-tracked. One animal inhibited only its fourth segment but never its sixth during the session, while another inhibited only its sixth but not its fourth.

These findings establish that the TI system is capable of differentially inhibiting the dendrites on different sides of the nerve cord or of different segmental ganglia. Further work is required to determine whether different branches of a single dendritic arbor are subject to differential TI.

\section{TI suppresses weak stimuli more than strong ones}

Inhibition located in the immediate vicinity of excitatory synapses can also interact with excitation in a manner that proximal inhibition would not. As the number or strength of excitatory inputs to a neuron increases, the resulting EPSP does not increase proportionately, because as the membrane potential approaches the excitatory synaptic reversal potential, the synaptic driving force diminishes (and also because contributions from each input are shunted by the conductances due to others). Eventually, EPSPs saturate at a maximum possible value. How- 

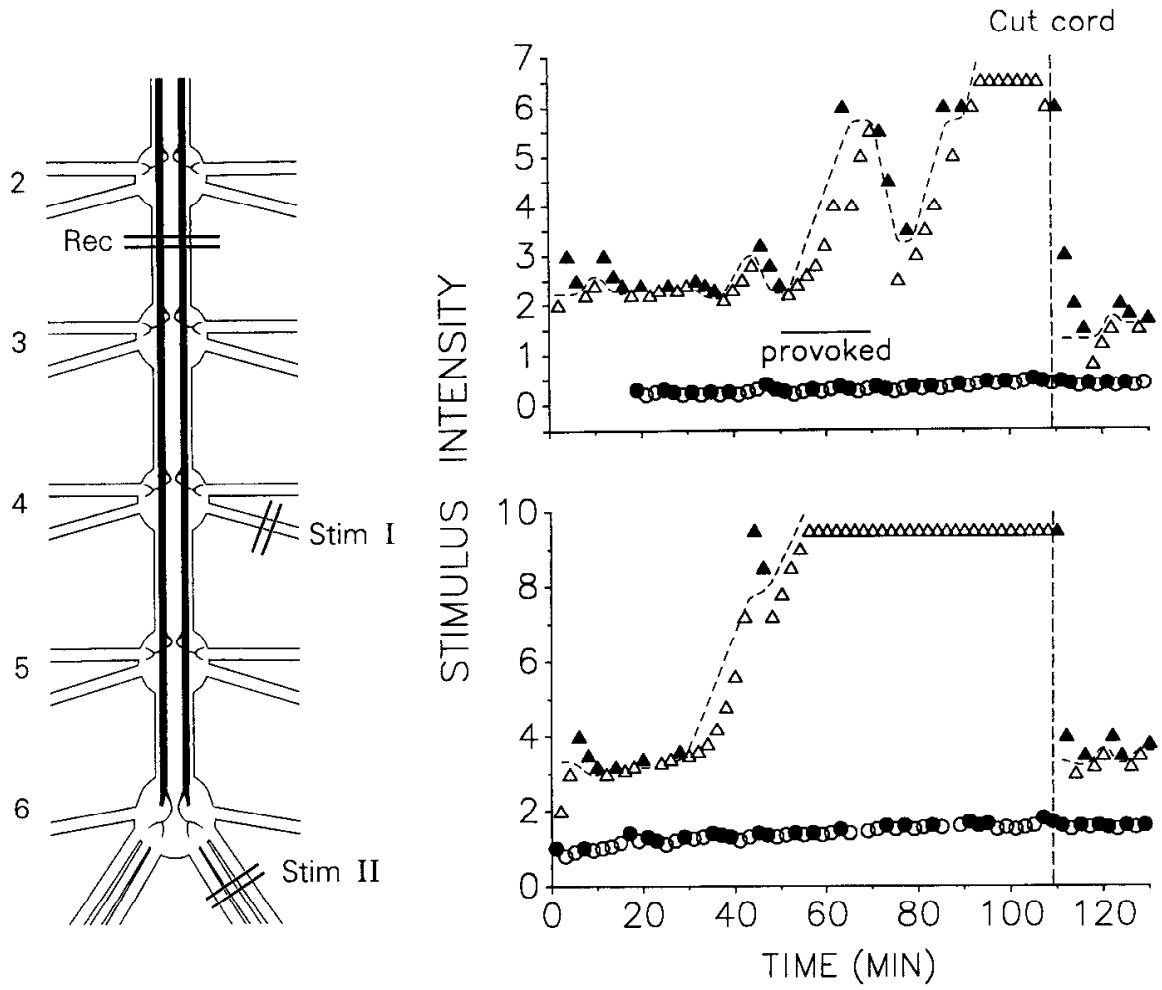

Figure 11. Temporal comparison of thresholds for firing of fourth and sixth segment LGs and sensory INs on left side of the animal. Plotting conventions and method of provocation are as in Figure 10. The cord was cut between thorax and abdomen at the vericial dashed line. Drawing to left shows tested segment corresponding to graph. ever, inhibitory input that occurs sufficiently close to excitatory input reduces depolarization at the point of EPSP generation and therefore has a substantial cffcet on the synaptic driving force. The significance of this important point will be considered in the Discussion. We present here results of simulations and measurements from LG illustrating the effects of inhibition on excitatory saturation.

Simulation results. The saturation process was simulated with a steady-state, two-compartment, equivalent circuit model (see Fig. 12 insets). For simplicity we assumed a uniform cable with the ratio of the transmembrane resistances $R_{D}$ and $R_{P}$ to the longitudinal resistance $R_{L}$ chosen so that attenuation of EPSPs from distal to proximal compartment was by a factor of 10 , as it is approximately in LG (Krasne, 1969; Zucker, 1972a; Vu, unpublished observations). Excitation was modeled as a driving voltage $E_{c}(100 \mathrm{mV})$ in series with a variable conductance $G_{e}$, just as chemical excitation is commonly modeled. Although excitation of $L G$ is via rectifying electrical synapses, this equivalent circuit holds to a first approximation. In this case, $E_{e}$ represents the average amplitude of the presynaptic spikes and $G_{c}$ the lumped conductances of all forward biased rectifying junctions (see Giaume et al., 1987; Edwards, 1990b). As the excitatory strength is increased by increasing $G_{e}$, the peak depolarization achieved increases rapidly at first but then plateaus, as shown by the top curves in Figure $12, A_{1}$ and $A_{2}$.

The interactions between excitation and proximal and distal inhibition were studied by adding proximal or distal inhibitory shunts $\left(G_{i}\right)$ to the model (Fig. 12 insets). The effects of proximal inhibition are shown in Figure $12 A_{1}$. Again, the top curve is the excitation curve without inhibition. The remaining curves show the effects of progressively greater amounts of proximal inhibition (i.e., increasing values of $G_{i}$ ). Because the excitatory input is electrotonically distant from the location of inhibition (and recording), the potentials generated in the distal compartment are little affected by inhibition and the effect of a given degree of inhibition is simply to attenuate the control excitation curve measured in the proximal compartment by an almost constant factor (Fig. 12B $B_{1}$ ).

The effects of distal inhibition are quite different (Fig. 12 $A_{2}$ ). Because the inhibition reduces depolarization of the dendritic region itself, it tends to counter the saturation process that develops as the dendritic depolarization approaches the excitatory synaptic reversal potential. This allows excitatory levels that in the uninhibited situation would produce no further potential change to do so, until the inhibition is overcome and excitation again saturates. Note that even with strong inhibition (e.g., the rightmost curve in Fig. $12 A_{2}$ ), the maximum achievable depolarization is virtually the same as that in the absence of inhibition.

We have obtained qualitatively similar results using more realistic models of neuronal dendritic arbors, including both uniform and tapering cables each with 10 compartments (cf. Rall, 1964) as well as an anatomically accurate model of LG receiving synaptic potentials that are similar in time course to observed ones (see Materials and Methods for values of model parameters and source of modeling program).

Simulation results from the latter model are illustrated in Figure 13. Excitation and distal inhibition were distributed on a subset of distal dendritic compartments, whereas proximal inhibition was placed only on the three compartments most proximal to the large "axonal" compartment (Fig. 13A). Consistent with known physiology (Krasne, 1969; Zucker, 1972a; $\mathrm{Vu}$, unpublished observations), the geometry of the model LG led to a roughly tenfold attenuation of EPSPs from the most distal dendrites to the proximal recording site. Direct measurement of voltage levels in a distal compartment showed that proximal inhibition had very little effect on the size of an EPSP generated there whereas distal inhibition (in the same com- 

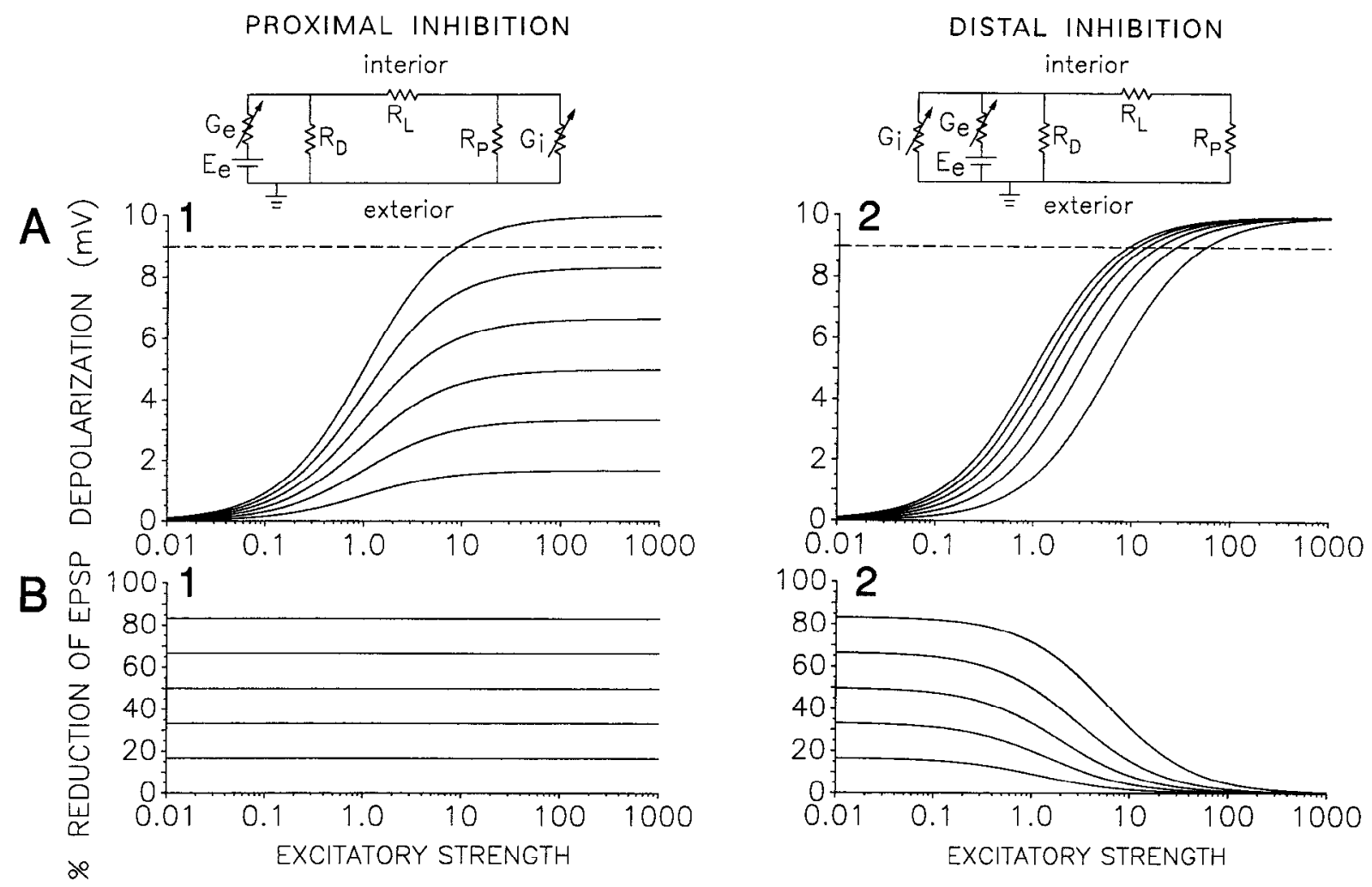

Figure 12. Computational distinction between proximal and distal inhibition. Circuit insets, $R_{D}$ and $R_{P}$ are resistances of distal and proximal compartments, respectively. Values of all circuit elements were expressed relative to that of $R_{P}$. $R_{L}$, longitudinal resistance between compartments, with $R_{p} /\left(R_{p}+R_{L}\right)=0.1 . G_{e}$ and $E_{e}$, variable conductance and driving force of distally located excitation $\left(E_{e}=100 \mathrm{mV}\right)$. The electrochemical battery for the resting potential was omitted for simplicity. Inhibition was modeled by the variable conductance $G_{i}$. $A$, Proximally measured steadystate depolarization as a function of distal excitation (varied by changing $G_{e}$ relative to $R_{p}$ ), in the presence of constant amounts of either proximal (1) or distal (2) inhibition. Curves were produced with increasing values of $G_{i} / G_{D}$ ( 0 for top curve, $0.2,0.5,1,2$, and 5 for successively lower curves; $\left.G_{D}=1 / R_{D}\right)$. The inhibitory reversal potential was assumed to be close in value to the resting potential. Dashed line, a hypothetical critical firing level of neuron as assessed in the proximal compartment. $B$, Percentage reductions of EPSPs for the inhibition curves in $A$.

partment) significantly reduced the EPSP (Fig. 13B), even though the strengths of the two types of inhibition were chosen to give comparable reductions of the EPSP when measured in the proximal compartment (about $60 \%$ reduction).

Figure 13, $C$ and $D$, indicates that peak EPSP size and percentage EPSP reduction as a function of excitatory strength were also affected by proximal and distal inhibition in the same manner that they were in the more general two-compartment model simulations of Figure 12. Proximal inhibition tended to reduce all EPSPs by a nearly constant factor (Fig. $13 D_{1}$ ), whereas distal inhibition reduccd small EPSPs more than large oncs (Fig. 13D $D_{2}$ ). Note that these properties hold true whether the inhibition is modeled with a reversal potential equal to the resting potential as in Figure 12 or with a reversal potential that produces an IPSP as in Figure 13 (and also confirmed for the two-compartment model but not shown).

Finally, additional simulations with the model LG neuron in Figure $13 A$ showed that when the experiment of Figure 8 was simulated by injecting current into the recording compartment, $V_{\text {prox }}$ was reduced considerably more by proximal than by distal inhibition that reduced EPSPs by a comparable amount (data not shown). This supports our conclusions regarding the sites of recurrent and tonic inhibition (see Fig. $8 \mathrm{C}$ ).

Experimental results. The functional implications of the difference in interaction of proximal and distal inhibition with excitation will be considered in the Discussion. However, we needed to address the question of whether TI, though demonstrated to be distal, in fact operated sufficiently closely to excitatory inputs to interact with excitation in the manner predicted by Figure $12 A_{2}$. Figure $12 B$, which shows the percentage attenuation of EPSP amplitudes produced by each type of inhibition, suggested a test. If TI is not sufficiently distal to affect EPSP amplitudes in the distal dendrites, then percentage attenuation will be independent of EPSP amplitude (Fig. 12 $B_{1}$ ), whereas if the inhibition does attenuate potentials at their origins, percentage attenuation will be greater for small than for large EPSPs (Fig. 12 $B_{2}$ ).

To evaluate this, we compared TI of small (average peak of $3.8 \mathrm{mV})$ and large $(6.1 \mathrm{mV})$ EPSPs in the same preparation for eight animals. The smaller EPSP was in fact always inhibited more strongly (20\% mean reduction for small EPSPs, $12 \%$ for large EPSPs; $t_{7}=5.67, p<0.001$; Fig. 14A). Data from one animal are illustrated in Figure $14 B$. The root-evoked EPSPs at two different stimulus amplitudes were repeatedly measured at their peaks (i.e., $\beta$-peaks). Periods with no TI (during sucrose block and after cord severance) were then compared to periods with TI. All measurements at each stimulus strength were normalized to the mean value in the absence of TI.

The equivalent test for recurrent inhibition (see Fig. 12 $B_{1}$ ) was impractical because of the additional inhibition at the first synapse of the LG circuit, preventing experimental generation of strong input to $L G$ during recurrent inhibition. 
A

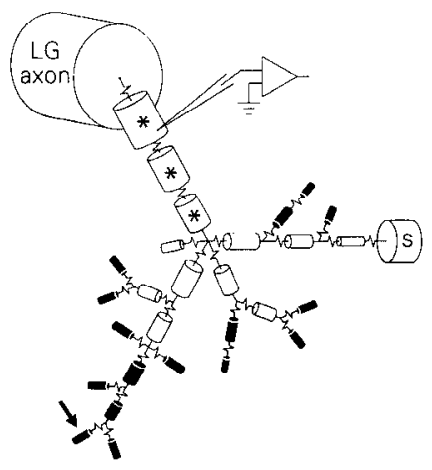

C
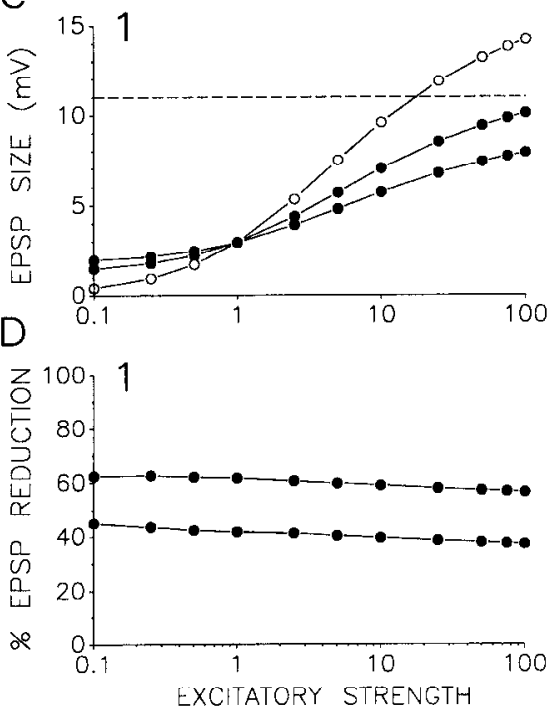

B

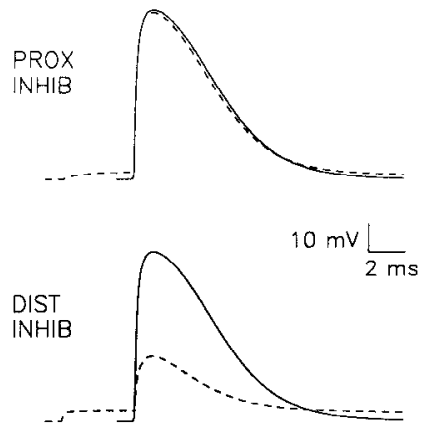

DISTAL
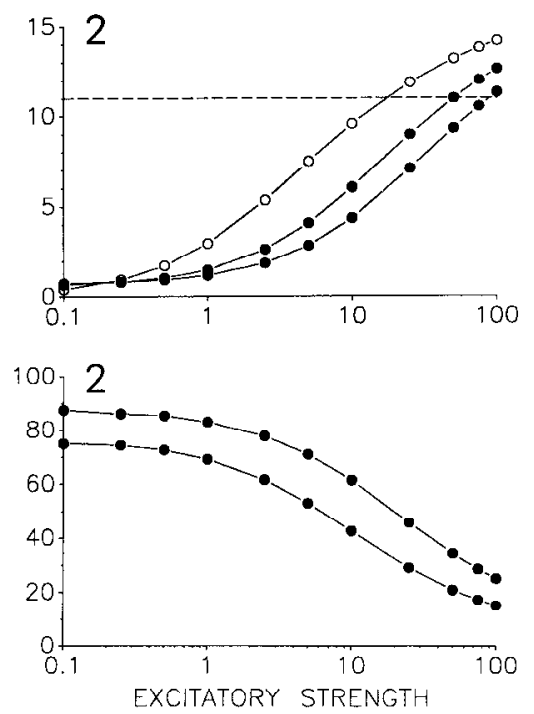

Figure 13. Simulations from multicompartment model of LG neuron. $A$, Diagram of model neuron. Excitatory and distal inhibitory synapses were placed on each shaded compartment; proximal inhibitory synapses were placed on the three compartments with asterisks. Traces in $B$ were measured from the compartment to which arrow is pointed; curves in $C$ and $D$ were produced from proximal measurements (compartment impaled by microelectrode). See Materials and Methods for further details of model. $B$, Effect of proximal and distal inhibition on the absolute size of an EPSP measured in a distal compartment. For each inhibition type, a control EPSP (solid trace) is superimposed on an inhibited EPSP (dashed trace). Note small, depolarizing IPSPs in both cases. $C$ and $D$, Same as in Figure 12, but measuring the peak of transiently produced EPSPs. In $C$, the absolute peak depolarization due to both EPSP and depolarizing IPSP was measured, whereas in $D$, EPSP size was measured relative to the membrane potential at the onset of the EPSP. Excitatory strength was normalized, with a value of 0.1 representing a $0.01 \mu \mathrm{S}$ peak conductance increase in each excited compartment. Peak proximal inhibitory conductance was $2.5 \mu \mathrm{S}$ for one curve and $5.0 \mu \mathrm{S}$ for the other; the corresponding values for distal inhibition were 0.6 and $1.35 \mu \mathrm{S}$. The hypothetical critical firing level (dashed line) shown in $C$ was not actually modeled with active conductances.

\section{Discussion}

The major finding of this study was that TI, like recurrent inhibition, is due to a depolarizing, conductance-increasing postsynaptic inhibition of the LGs, but that the locus of the synapses producing the two types of inhibition is different. Recurrent inhibition occurs proximally near the initial segment and spike initiating zone of the axon, whereas TI occurs distally in electrotonically distant dendrites. We discuss first the significance of this observation.

\section{Absolute versus relative inhibition}

Why should the locus of inhibition be different for recurrent and tonic inhibition? Ideally, we would like to understand this in terms of the functional requirements of each type of inhibition. The function of recurrent inhibition seems clear: firing of the LGs during the execution of a previously initiated escape response would certainly upset the form of the response and maladaptively alter the animal's trajectory through the water. Therefore, no matter how strong the environmental stimulus, the crayfish should never be able to start a new escape response while one is in progress. Thus, recurrent inhibition should be absolute in its effect; no stimulus of any strength should be able to override it.

Although the uses made of TI are only partially understood, what we know of its operation suggests that it is evoked in situations where inhibition may be adaptive for strategic reasons but is not essential. For example, the inhibition of escape during feeding makes adaptive sense because it is worth the risk of ignoring a mild threat, such as that from a conspecific, in order to continue the consumption of available food (see Bellman and Krasne, 1983). But from a sufficiently serious threat the feeding animal should break off consumption and flee. Similarly, once firmly caught by a predator or an experimenter, execution of tailflips is relatively unlikely to lead to effective escape and may be energetically wasteful; a defensive strategy of inhibiting escape may then be more adaptive (for related examples of defensive immobility, see Gallup et al., 1971; Bolles and Riley, 1973; Bouton and Bolles, 1980). However, it might continue to be adaptive in this situation to respond to more injurious strikes with escape reactions. Thus, inhibition used for strategic purposes should be relative rather than absolute; suitable stimuli should be able to override it.

\section{Rationale for using proximal or distal inhibition}

We propose that the different functional requirements of recurrent and tonic inhibition provide an explanation for the proximality of recurrent inhibition and the distalness of TI.

Consider first proximal inhibition. The curves in Figure $12 A_{1}$ indicate that proximal inhibition decreases EPSP amplitude by a nearly constant factor independent of the amount of excitation. Thus, if the inhibitory strength were sufficient to reduce the 


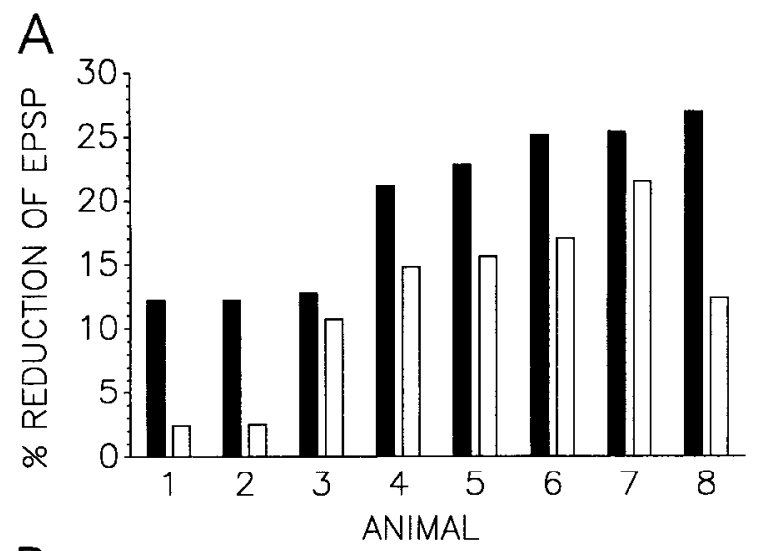

B

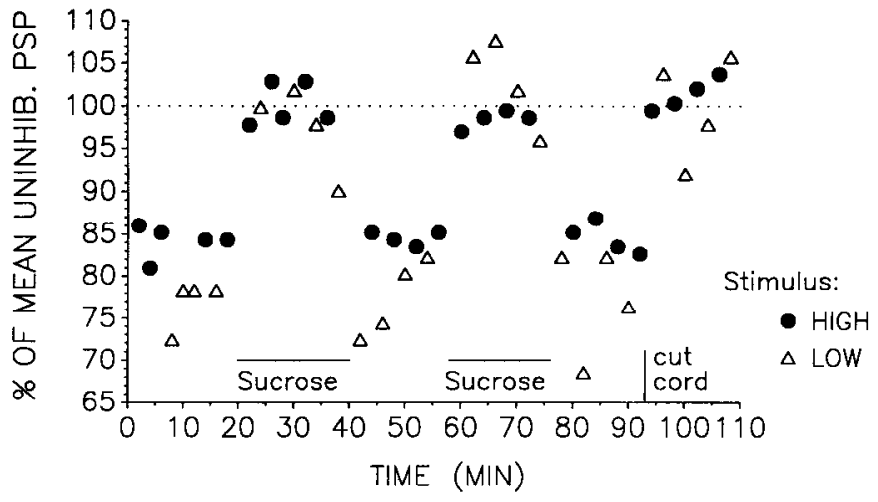

Figure 14. TI suppresses weak stimuli more than strong ones. $A$, Attenuation of small (solid bars) and large (open bars) EPSPs compared in the same animals. $B$, Normalized size of $\beta$ at two different stimulus levels over an entire session for one animal. For each stimulus level, all values were normalized to the mean of the values during sucrose block and after cord severance. Sucrose, periods during which sucrose block was applied. The high stimulus produced a maximal uninhibited $\beta$ of about $5.20 \mathrm{mV}$, while the low stimulus produced an uninhibited $\beta$ of approximately $2.65 \mathrm{mV}$.

plateau of the excitation curve to a level below the critical firing level of the proximal compartment (e.g., the dashed line in Fig. $12 A_{1}$ ), then no amount of additional excitation would fire the cell. In other words, the inhibition would be absolute, which is precisely the requirement for recurrent inhibition.

Distal inhibition behaves very differently. As described in Results, it tends to counter the dendritic excitatory saturation process, allowing excitatory levels that in the uninhibited situation would produce no further potential change to do so, until the inhibition is overcome and excitation again saturates. Thus, any amount of distal inhibition can be overcome by further excitation, as reflected in Figure $12 A_{2}$ by the fact that all curves generated with distal inhibition crossed the critical firing level with strong enough excitation. Consequently, distal inhibition is relative; it can be overridden, precisely as required for TI.

The distinction between proximal and distal inhibition illustrated in Figure 12 may also be seen in terms of their differing effects on repetitive firing to sustained depolarizing input (cf. Terzuolo et al., 1968). Proximal inhibition will tend to reduce the maximum firing rate of the cell, whereas distal inhibition will make the cell less responsive but still able to fire at the highest rate achievable in the absence of inhibition. In essence, the dynamic range of the postsynaptic cell is reduced by proximal but unaffected by distal inhibition.

\section{Assumptions}

The properties of TI, and of distal inhibition in general, illustrated in Figures 12 and 13 depend on compound EPSPs becoming sufficiently large near their dendritic origin to approach saturation. This is the case for the LGs. EPSPs recorded in larger branches of relatively distal dendrites can in fact exceed $80 \mathrm{mV}$ (Zucker, 1972a; Vu, unpublished observations), a sufficient level to "reverse-bias" the rectifying electrical synapses exciting LG as well as reduce the transjunctional voltage that drives current into the postsynaptic cell, thus diminishing the effect of additional excitation (see Giaume et al., 1987; Edwards, 1990a; Edwards et al., 1991). That dendritic EPSP sizes approach saturation levels is also supported by evidence obtained by Edwards ct al. (1991) that the root-cvoked EPSP decreases with artificial LG depolarization and increases with hyperpolarization, though the effect on later parts of the postsynaptic potential can be partly attributed to a postexcitatory, conductance-increasing inhibition (Krasne et al., 1990; Vu and Krasne, unpublished observations).

The absoluteness of recurrent inhibition, and more generally of proximal inhibition, depends on EPSPs being generated at substantial electrotonic distances from the cell's spike initiating zone, while inhibitory synapses occur close to it. LG EPSPs are in fact attenuated by about a factor of 10 from relatively distal dendrites to our usual proximal recording site (Krasne, 1969; Zucker, 1972a; Vu, unpublished observations), although the electrotonic distance may be less than implied by the extent of attenuation seen because some attenuation is probably due to capacitative shunting of the relatively brief electrical EPSPs. Although our non-steady-state simulations with an anatomically realistic multicompartmental model of LG (Fig. 13) gave results that were qualitatively similar to those analytically derived in Figure 12, a quantitative analysis of the distribution of excitatory synapses on the LG dendrites would be required to address this issue further.

Large dendritic EPSPs and large attenuation factors at the initial segment of the axon are thought not to be uncommon; they are predicted by realistic models of neurons and have been observed in intradendritic recordings from a variety of neurons (e.g., Llinas and Nicholson, 1971; Wong et al., 1979; Llinas and Sugimori, 1980; Schwartzkroin and Prince, 1980; Masukawa and Prince, 1984; Poolos and Kocsis, 1990; Turner and Richardson, 1991). In addition, it is well known that the active dendritic conductances found in many vertebrate neurons greatly contribute to the nonlinearity of excitation in these neurons. Finally, simulation studies have suggested that excitation placed on dendritic spines has a greater tendency to be nonlinear and to saturate (see Koch and Poggio, 1983; Perkel and Perkel, 1985; Rall and Segev, 1987; Shepherd et al., 1990).

The critical firing level of LG appears to be just below the saturation level of EPSPs (Krasne, 1969; see Krasne and Wine, 1987), making absolute inhibition relatively easy to achieve with proximal inhibitory inputs and necessitating distal inputs to obtain relative inhibition. In principle, it would be possible to override proximal inhibition and cause firing with stronger excitation if a cell's critical firing level (or the level of depolarization causing the maximal possible firing rate) were low relative to the excitatory saturation level. However, achieving relative inhibition in this manner would have two potentially costly consequences: (1) absolute inhibition of the same neuron would then require very large inhibitory conductances, and (2) rather 
small EPSPs would trigger firing, and thus for the EPSP size to be a relatively continuous function of input strength, unitary EPSPs would have to be very small. In effect, the signal-to-noise ratio of the system would then be reduced.

\section{Generality of distal and relative inhibitions}

Like the LGs, many neurons in higher CNSs receive both proximal and distal inhibitory innervation (see, e.g., Nicoll, 1969; Gottlieb and Cowan, 1972; Leung, 1978; Fujita, 1979; Wong and Prince, 1979; Alger and Nicoll, 1982; Masukawa and Prince, 1984; Mori et al., 1984). We propose that the specific requirement for absolute or relative inhibition in many tasks that neural circuits perform could partly account for the dual presence of proximal and distal inhibition when the former alone would seem sufficient and perhaps morc efficient. Thus, when computational requirements dictate that inhibition be absolute, we would expect proximally placed inhibitory synapses. On the other hand, when it is necessary that inhibition be overridden by sufficient excitation, or when it is necessary to decrease the responsiveness of a neuron without reducing its dynamic range, distal inhibition should be employed. Such relative inhibition is implied, for example, in lateral inhibition for contrast enhancement or direction selectivity in sensory systems (Koch et al., 1986). It has also been implicitly assumed in the rules for calculating "net" input in the processing units of parallel distributed processing networks (see Rumelhart et al., 1986) and in circuits for producing dynamic thresholds in learning models of the cerebellum and neocortex (Marr, 1969, 1970). Thus, though our data are specific to a crayfish neuron, we suggest that the frequent requirement for relative inhibition in neuronal computations may be a significant reason for the ubiquity of distal inhibition in nervous systems.

\section{Selective TI}

Distal inhibition is commonly thought to be an adaptation for selective inhibition of parts of a dendritic tree (Rall, 1964; Llinas, 1975; Koch et al., 1982; Jack et al., 1983; Shepherd and Koch, 1990). Although relatively little is known of the usages made of TI, a capacity for suppression of responses to some inputs but not others is not an implausible attribute for a form of inhibition conjectured to be used for strategic ends. However, such a capacity would imply that the tonic inhibitory system is sufficiently complex to suppress different dendritic fields independently. Given the relatively small number of neurons in the crayfish CNS and the tendency in this system to accomplish whole functions with single or small sets of neurons, we had expected that TI would instead be distributed to all its targets throughout the abdomen by a single, bilateral pair of descending interneurons. Thus, it was with considerable surprise that we found evidence for selectivity at least to different segmental LGs, implying an unexpectedly articulated inhibitory pathway. Whether selective inhibition of portions of the LG dendritic arbor within a single ganglion can occur remains to be seen.

\section{Circuit locus of $T I$}

Experiments using extracellular recording in chronic preparations originally suggested that $\mathrm{TI}$ only reduced transmission between $L G$ and its monosynaptic inputs and did not affect transmission at prior sensory network synapses or at synapses within motor pattern-generating circuitry (Krasne and Wine, 1975; Krasne and Lee, 1988). This conclusion formed the basis for more general inferences about the organization of neural circuits (Krasne and Wine, 1987; Krasne and Lee, 1988). However, the claim that transmission at the first synapse of the circuit was unaffected during TI was based on studying the responsiveness of only two representative sensory INs. The observation made here that disynaptic input to the LGs is not inhibited more than monosynaptic input greatly strengthens the above conclusion, for if TI affected transmission to a sizable number of sensory INs as well as postsynaptically inhibiting LG itself, then disynaptic input to $L G$ should have been reduced more than monosynaptic input.

\section{Behavioral context of neural activity}

We have proposed that perhaps there is a general correspondence between proximality and absoluteness of inhibition on the onc hand and distalness and relativity on the other. This proposal arose from our attempts to understand why recurrent and tonic inhibition in the crayfish should exert their effects on different parts of the LG neuron. Whether our general conjecture is correct remains to be seen. Nevertheless, we point out that this hypothesis on the function of a common but not wellunderstood feature of nervous systems arose from studying neural mechanisms in a circuit that directly produces behavior. The present study illustrates that a major advantage of studying invertebrate neural circuits is that the functional implications of details of neural organization that might otherwise remain obscure are relatively easier to discover because in invertebrate preparations one can often discern the behavioral consequences of neural activity.

\section{References}

Alger BE, Nicoll RA (1982) Feed-forward dendritic inhibition in rat hippocampal pyramidal cells studied in vitro. J Physiol (Lond) 328: 105-123.

Beall SP, Langley DJ, Edwards DH (1990) Inhibition of escape tailflip in crayfish during backward walking and the defense posture. J Exp Biol 152:577-582.

Bellman KL, Krasne FB (1983) Adaptive complexity of interactions between feeding and escape in crayfish. Science 221:779-781.

Bolles RC, Riley AL (1973) Freezing as an avoidance response: another look at the operant-respondent distinction. Learn Motiv 4:268-275.

Bouton ME, Bolles RC (1980) Conditioned fear assessed by freezing and the suppression of three different baselines. Anim Learn Behav $8: 429-434$

Byrne JH (1987) Cellular analysis of associative learning. Physiol Rev 67:329-439.

Edwards DH (1990a) Mechanisms of depolarizing inhibition at the crayfish giant motor synapse. I. Electrophysiology. J Ncurophysiol 64:532-540.

Edwards DH (1990b) Mechanisms of depolarizing inhibition at the crayfish giant motor synapse. II. Quantitative reconstruction. J Neurophysiol 64:541-550.

Edwards DH, Simon TW, Leise EM, Fricke RA (1988) Crayfish "backward walking" neurons inhibit LG command neuron. Soc Neurosci Abstr 14:999.

Edwards DH, Heitler WI, Leise EM, Fricke RA (1991) Postsynaptic modulation of rectifying electrical synaptic inputs to the LG escape command neuron in crayfish. J Neurosci 11:2117-2129.

Fraser K, Heitler WJ (1989) Thoracic output of crayfish giant fibres. II. The segmental giant neurone. J Comp Physiol [A] 166:125-132.

Fraser K, Heitler WJ (1991) Photoinactivation of the crayfish segmental giant neuron reveals a direct giant-fiber to fast-flexor connection with a chemical component. J Neurosci 11:59-71.

Fujita $Y$ (1979) Evidence for the existence of inhibitory postsynaptic potentials in dendrites and their functional significance in hippocampal pyramidal cells of adult rabbits. Brain Res 175:59-69.

Gallup GG, Nash RF, Ellison AL (1971) Tonic immobility as a reaction to predation: artificial eyes as a fear stimulus for chickens. Psychonom Sci 23:79-80. 
Giaume C, Kado RT, Korn H (1987) Voltage-clamp analysis of a crayfish rectifying synapse. J Physiol (Lond) 386:91-1 12.

Gottlieb DI, Cowan WM (1972) On the distribution of axonal terminals containing spheroidal and flattened synaptic vesicles in the hippocampus and dentate gyrus of the rat and cat. Z Zellforsch 129: 413-429.

Jack JJB, Noble D, Tsien RW (1983) Electric current flow in excitable cells. Oxford: Clarendon.

Johnson GE (1924) Giant nerve fibres in crustaccans with spccial reference to Cambarus and Palaemonetes. J Comp Neurol 36:323373.

Kandel ER, Schwartz JH (1982) Molecular biology of learning: modulation of transmitter release. Science 218:433-443.

Kandel ER, Klein M, Hochner B, Shuster M, Siegelbaum SA, Hawkins RD, Glanzman DL, Castellucci VF, Abrams TW (1987) Synaptic modulation and learning: new insights into synaptic transmission from the study of behavior. In: Synaptic function (Edelman GM, Gall WE, Cowan WM, eds), pp 471-518. New York: Wiley.

Kennedy D (1971) Crayfish interneurons. Physiologist 14:5-30.

Kirk MD (1985) Presynaptic inhibition in the crayfish CNS: pathways and synaptic mechanisms. J Neurophysiol 54:1305-1325.

Kirk MD, Wine JJ (1984) Identified interneurons produce both primary afferent depolarization and presynaptic inhibition. Science 225 : 854-856.

Koch C, Poggio T (1983) A theoretical analysis of electrical properties of spines. Proc R Soc Lond [Biol] 218:455-477.

Koch C, Poggio T, Torre V (1982) Retinal ganglion cells: a functional interpretation of dendritic morphology. Philos Trans R Soc Lond [Biol] 298:227-264.

Koch C, Poggio T, Torre V (1986) Computations in the vertebrate retina: gain enhancement, differentiation and motion discrimination. Trends Neurosci 9:204-211.

Krasne FB (1969) Excitation and habituation of the crayfish escape reflex: the depolarizing response in lateral giant fibers of the isolated abdomen. J Exp Biol 50:29-46.

Krasne FB, Glanzman DH (1986) Sensitization of the crayfish lateral giant escape reaction. J Neurosci 6:1013-1020.

Krasne FB, Lee SC (1988) Response-dedicated trigger neurons as control points for behavioral actions: selective inhibition of lateral giant command neurons during feeding in crayfish. J Neurosci 8:37033712 .

Krasne FB, Wine JJ (1975) Extrinsic modulation of crayfish escape behavior. J Exp Biol 63:433-450.

Krasne FB, Wine JJ (1984) The production of crayfish tailflip escape responses. In: Neural mechanisms of startle behavior (Eaton RC, ed), pp 179-211. New York: Plenum.

Krasne FB, Wine JJ (1987) Evasion responses of the crayfish. In: Aims and methods in neuroethology (Guthie DM, ed), pp 10-45. Manchester: Manchester UP.

Krasne FB, Vu ET, Lee SC (1990) The excitability of the crayfish lateral giant escape reaction: inhibitory control of the lateral giant dendrites. In: Frontiers in crustacean neurobiology (Wiese K, Krenz W-D, Tautz J, Reichert H, Mulloney B, eds), pp 316-322. Berlin: Birkhauser

Krasne FB, Vu ET, Lee SC (1991) Differential tonic inhibition of crayfish lateral giant escape to stimuli in different sensory fields. Soc Neurosci Abstr 17:1057.

Lee SC, Krasne FB (1993) Ultrastructure of the circuit providing input to the crayfish lateral giant neurons. J Comp Neurol 327:271-288.

Leung LS (1978) Hippocampal CAl region-demonstration of antidromic dendritic spike and dendritic inhibition. Brain Res 158:219222.

Llinas $R$ (1975) Electroresponsive properties of dendrites in central neurons. Adv Neurol 12:1-13.

Llinas R, Nicholson C (1971) Electrophysiological properties of dendrites and somata in alligator Purkinje cells. J Neurophysiol 34:532551 .

Llinas R, Sugimori M (1980) Electrophysiological properties of in vitro Purkinje cell dendrites in mammalian cerebellar slices. J Physiol (Lond) 305:197-213.

Marr D (1969) A theory of cerebellar cortex. J Physiol (Lond) 202: $437-470$.

Marr D (1970) A theory for cerebral neocortex. Proc R Soc Lond [Biol] 176:161-234.
Masukawa LM, Prince DA (1984) Synaptic control of excitability in isolated dendrites of hippocampal neurons. J Neurosci 4:217-227.

Miller MW, Vu ET, Krasne FB (1992) Cholinergic transmission at the first synapse of the circuit mediating the crayfish lateral giant escape reaction. J Neurophysiol 68:2174-2184.

Mori E, Nowycky MC, Shepherd GM (1984) Synaptic excitatory and inhibitory interactions at distal dendritic sites on mitral cells in the isolated turtle olfactory bulb. J Neurosci 4:2291-2296.

Nicoll RA (1969) Inhibitory mechanisms in the rabbit olfactory bulb: dendrodendritic mechanisms. Brain Res 14:157-172.

Perkel DH, Perkel DJ (1985) Dendritic spines: role of active membrane in modulating synaptic efficacy. Brain Res 325:331-335.

Poolos NP, Kocsis JD (1990) Dendritic action potentials activated by NMDA receptor-mediated EPSPs in CAl hippocampal pyramidal cells. Brain Res 524:342-346.

Rall W (1964) Theoretical significance of dendritic trees for neuronal input-output relations. In: Neural theory and modeling (Reiss RF, ed), pp 73-97. Stanford, CA: Stanford UP.

Rall W, Segev I (1987) Functional possibilities for synapses on dendrites and dendritic spines. In: Synaptic function (Edelman GM, Gall WE, Cowan WM, eds), pp 605-636. New York: Wiley.

Roberts AM (1968) Recurrent inhibition in the giant-fibre system of the crayfish and its effect on the excitability of the escape response. J Exp Biol 48:545-567.

Rumelhart DE, Hinton GE, McClelland JL (1986) A general framework for parallel distributed processing. In: Parallel distributed processing, Vol 1, Foundations (McClelland JL, Rumelhart DE, eds), pp 45-76. Cambridge, MA: MIT Press.

Schwartzkroin PA, Prince DA (1980) Changes in excitatory and inhibitory synaptic potentials leading to epileptogenic activity. Brain Res 183:61-76.

Shepherd GM, Koch C (1990) Dendritic electrotonus and synaptic integration. In: The synaptic organization of the brain, 3d ed (Shepherd GM, ed), pp 439-473. New York: Oxford UP.

Shepherd GM, WoolfTB, Carnevale NT (1990) Comparisons between active properties of distal dendritic branches and spines: implications for neuronal computations. J Cognit Neurosci 1:273-286.

Sigvardt KA, Hagiwara G, Wine JJ (1982) Mechanosensory integration in the crayfish abdominal nervous system; structural and physiological differences between interneurons with single and multiple spike initiating sites. J Comp Physiol 148:143-157.

Terzuolo CA, Purple RL, Bayly E, Handelman E (1968) Postsynaptic inhibition-its action upon the transducer and encoder systems of neurons. In: Structure and function of inhibitory neuronal mechanisms (von Euler C, Skoglund S, Soderherg U, eds), pp 261-289. New York: Pergamon.

Turner RW, Richardson TL (1991) Apical dendritic depolarizations and field interactions evoked by stimulation of afferent inputs to rat hippocampal CA1 pyramidal cells. Neuroscience 42:125-135.

Van Harreveld A (1936) A physiological solution for freshwater crustaceans. Proc Soc Exp Biol Med 34:428-432.

Vu ET, Krasne FB (1988) Intracellular correlates of restraint-induced modulation of the crayfish lateral giant escape response. Soc Neurosci Abstr 14:838.

Vu ET, Krasne FB (1989) Postsynaptic inhibition of the lateral giant neuron during restraint-induced suppression of crayfish escape. Soc Neurosci Abstr 15:1141.

Vu ET, Krasne FB (1991) Evidence for a proposed computational property of remote dendritic inhibition obtained during inhibitory control of crayfish escape behavior. Soc Neurosci Abstr 17:550.

$\mathrm{Vu}$ ET, Krasne FB (1992) Evidence for a computational distinction between proximal and distal neuronal inhibition. Science 255:17101712.

Watanabe A, Grundfest H (1961) Impulse propagation at the septal and commissural junctions of crayfish lateral giant axons. J Gen Physiol 45:267-308.

Wine JJ (1984) The structural basis of an innate behavioural pattern. J Exp Biol 112:283-319.

Wine JJ, Krasne FB (1982) The cellular organization of crayfish escape behavior. In: The biology of crustacea, Vol 4 (Sandeman DC, Atwood HL, eds), pp 241-292. New York: Academic.

Wong RKS, Prince DA (1979) Dendritic mechanisms underlying penicillin-induced epileptiform activity. Science 204:1228-1230. 
Wong RKS, Prince DA, Basbaum AI (1979) Intradendritic recordings from hippocampal neurons. Proc Natl Acad Sci USA 76:986-990.

Zucker RS (1972a) Crayfish escape behavior and central synapses. I. Neural circuit exiting lateral giant fiber. J Neurophysiol 35:599-620.
Zucker RS (1972b) Crayfish escape behavior and central synapses. II. Physiological mechanisms underlying behavioral habituation. J Neurophysiol 35:621-637. 